Research Article

\title{
Suspender Replacement Method for Long-Span Concrete-Filled Steel Tubular Arch Bridges and Cable Force Measurement Based on Frequency Method
}

\author{
Yulin Deng (i) and Luming Deng (D) \\ Department of Road and Bridge Engineering, School of Transportation and Logistics Engineering, \\ Wuhan University of Technology, Wuhan 430063, China \\ Correspondence should be addressed to Yulin Deng; dengyulin@whut.edu.cn
}

Received 31 July 2021; Accepted 2 September 2021; Published 20 September 2021

Academic Editor: Guojun Wu

Copyright (c) 2021 Yulin Deng and Luming Deng. This is an open access article distributed under the Creative Commons Attribution License, which permits unrestricted use, distribution, and reproduction in any medium, provided the original work is properly cited.

\begin{abstract}
The suspenders on the sides of an arch bridge are highly vulnerable to damage caused by traffic load and environmental corrosion. To accurately estimate the cable force of suspenders, herein, we analyse the influencing factors through a suspender tension test based on the principle of suspender vibration. The frequency of each suspender of the bridge is evaluated using the frequency method. By combining the cable force data measured directly and the measured suspender frequency, the formulas for calculating the cable forces of long and short suspenders are fitted, and a reasonable estimation method for the calculated length of short suspenders is provided. The formulas are verified through application to a CFST arch bridge. Results indicate that the proposed formula effectively considers the influence of the sleeve on the overall calculated length of the suspender. The formula calculates the suspender cable force with higher accuracy, proving its suitability for engineering use.
\end{abstract}

\section{Introduction}

Suspenders are widely used in arch bridges and suspension bridges owing to their light weight and strong tensile bearing capacity. The mechanical characteristics of the suspender components during their service life not only affect their reliability but also have an important effect on the overall load transfer and internal force distribution of the bridges. The accurate measurement of the hanger cable force is of great significance not only in the construction phase but also in the maintenance phase. In engineering practice, hydraulic jacks or load sensors are often used to measure the hanger cable force. However, the measurement results obtained using the former are often uncertain, whereas the measurement methods using the latter are expensive. In the case of slender suspenders, the tension based on classical string vibration theory has a quadratic linear relationship with frequency; moreover, the vibration frequency method is more economical than the pressure sensor method, pressure gauge method, and inverse magnetostrictive effect method [1]. Owing to the stiffness of the suspenders, complex boundary conditions, use of shorter suspenders, and significant influence of liners, among other factors in a halfthrough concrete-filled steel tubular arch bridge, different formulas should be fitted for different suspenders when using the frequency method to calculate the cable force, and the calculation length should be revised for short suspenders [2-4].

Retrofitting of concrete cable-stayed bridges in service has become an issue of utmost importance globally. In general, the suspender replacement methods can be classified into three types, namely, temporary suspension rod method, temporary sling method, and bridge deck support method [5-7]. Lan et al. proposed a simplified method for arch bridge suspender replacement based on the measured displacement correction to ensure safety during suspender replacement through the pocket hanging method [8]. Considering the premature failure of the short suspender of 
a suspension bridge, Sun et al. adopted a method of combining data monitoring and finite element simulation to propose and realise the replacement of a failed short suspender [9]. Feng et al. introduced the suspension bridge suspender replacement process. A three-dimensional finite element model was used to determine the lifting force during the sling replacement process, and an advanced visual-based sensor was used for noncontact force measurement [10]. Thus, suspender replacement is considered as one of the most important approaches to preserve and potentially extend the service life of existing concrete cable-stayed bridges.

Evidently, the substantial reduction in the service life of the stay cables is the main reason for cable replacement in a concrete cable-stayed bridge while in service. Therefore, accurate measurement of the suspender cable force is of great significance to the structural safety of the bridge. Kim and Park [11] proposed the estimation of sling tension using the frequency method, and studied the influence of sagelongation and bending stiffness on the calculation accuracy of this method, which was verified through laboratory tests. He et al. [12] considered the complex boundary conditions of suspenders based on the Euler-Bernoulli quantity theory, established an implicit analytical expression of the relationship between the suspender tension and its transverse vibration frequency under complex boundary conditions, and presented a method to determine the parameters in the expression. Wu et al. [13] considered the specific layout of the suspender boundary constraints of an arch bridge and directly estimated the cable force of the suspender by considering the effective vibration length at the upper end of the suspender as the distance between the continuation boundary and the visual angle boundary. Yan et al. [14] proposed a new method to calculate the internal force of stay cables under complex boundary conditions. This method transforms the cable force estimation problem from the general process of constructing and solving the cable motion equation to a simple problem of determining the zeroamplitude point of the vibration mode. The proposed method can produce accurate cable force estimation regardless of the complexity of the boundary conditions. Zarbaf et al. [15] proposed a cable force estimation method for a cable-stayed bridge based on the frequency method. By extracting the natural frequencies of the stay cables, the identified natural frequencies and measurable experimental characteristics of the stay cables were input into a stay cable model, which could simulate the bending stiffness and sag of the stay cables, and then the cable tension of the cable-stayed bridges was calculated. Chen et al. [16] derived the frequency equations for cable vibration under different boundary conditions. According to the expressions for the dimensionless parameter, it was confirmed that the modal functions related to the complex boundary conditions were mainly contributed by the sinusoidal components. Based on this finding, a similar formula was proposed to determine the cable force under the assumption of hinge constraints at both ends. Based on the stiffness theory, $\mathrm{Xu}$ et al. [17] established a three-stage suspender dynamic model by considering the influence of the suspender anchorage zone, and solved it by using the particle swarm optimisation algorithm, thus estimating the suspender cable force. Ma et al. [18] selected six practical calculation formulas for a single cable force based on the frequency for error analysis. By focusing on the shortcomings of the existing calculation methods, they proposed a cable force measurement method based on the first-order frequency test to calibrate the tensile structure cables.

In this study, in combination with the current model of the relationship between the suspender cable force and its natural frequency, a suspender cable force estimation method, which considers the calculated length of the short suspender and lateral bending stiffness, is proposed, and different suspenders are fitted accordingly [18-20]. A tension test is conducted on the suspenders based on the principle of vibration to identify the influential parameters of the cable force. The formula for collecting the cable forces of long and short suspenders as well as an estimation method for the calculation length of short suspenders is presented. This method is applied to the suspender cable force estimation of a half-through concrete-filled steel tubular arch bridge. Through comparison with the suspender cable force after replacement and prior cable force records, the effectiveness of the cable force estimation formula fitted using this method is demonstrated. Based on the estimated result of the new formula, the old suspender with severe corrosion could be replaced reasonably by using temporary suspenders.

\section{Overview of Suspender Replacement Method}

The suspender replacement method can be classified into two types depending on whether temporary support is needed: (a) temporary support replacement; (b) nontemporary support replacement. Although the nontemporary support replacement is simple to perform and requires less construction equipment, it requires a higher overall stiffness of the bridge structure. In engineering practice, the spans of existing suspender arch bridges are large, thereby restricting the overall stiffness of the bridges. In addition, the process of directly cutting the suspender generates an impact, which can easily cause vibrations and may even damage the bridge. Therefore, the nontemporary support replacement method was not selected in this replacement construction.

In the temporary replacement system, the construction operation at the time of the specific replacement can be classified into the following three methods: the bridge deck support method, temporary suspender method, and temporary hoisting method. The advantages and disadvantages of the three replacement methods are listed in Table 1.

When selecting the method for the suspender replacement, it is necessary to comprehensively consider the state of the bridge and state of service. Complete blockade of traffic can ensure construction safety with an adequate working space and reduce the degradation of linear control of the bridge due to vehicular traffic. However, the bridge is an important highway with heavy traffic; therefore, it is unrealistic to close the highway completely. Under the semi- 
TABLE 1: Suspender replacement method.

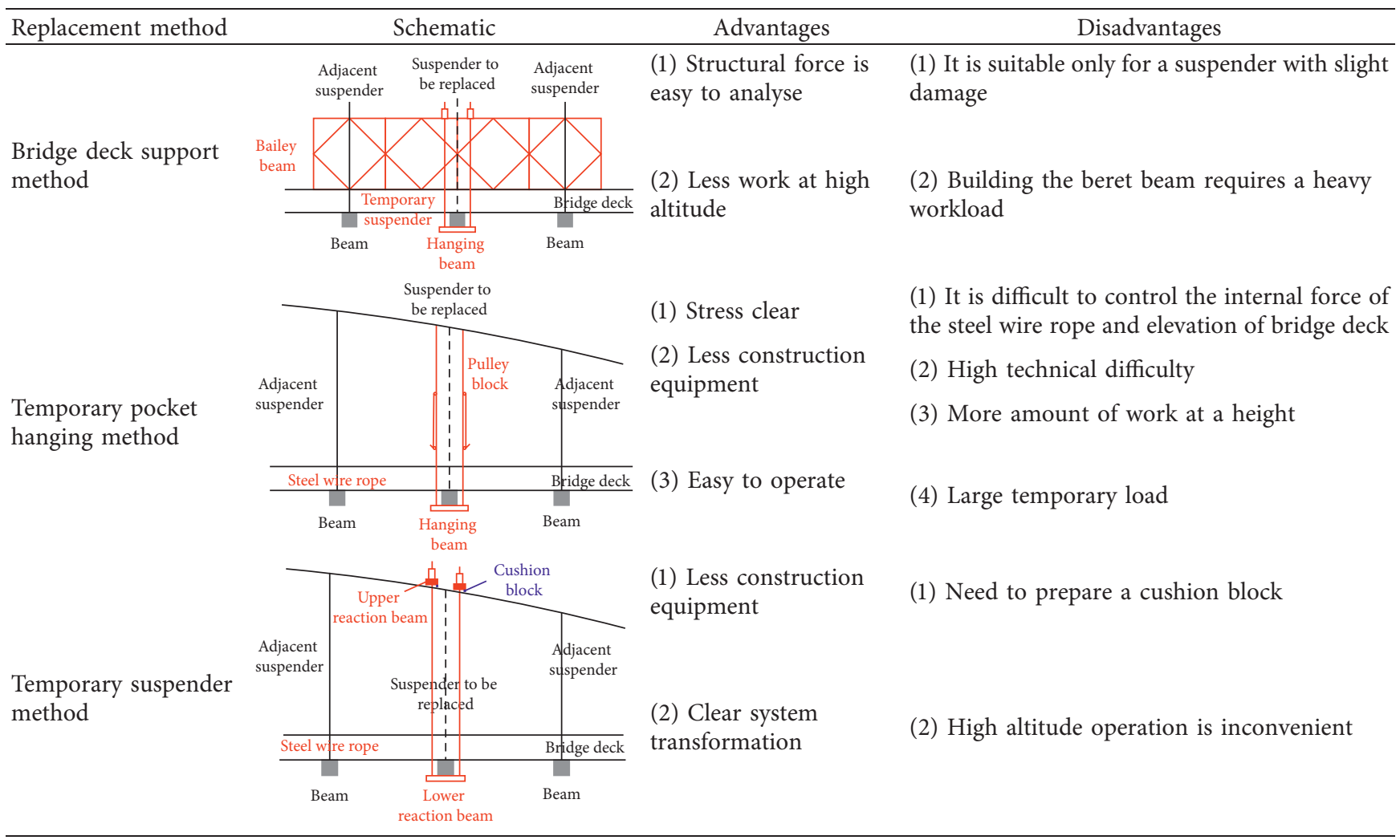

closed traffic condition and constant daily traffic flow, uneven vehicle density is caused on the bridge due to higher vehicle density in the unclosed lane. Considering multiple factors, the suspender replacement plan should ensure as few procedures as possible, convenient construction, short construction period, and less bridge deck occupancy while minimising the effect on traffic. In addition, it should have better economy, feasibility, and safety. Therefore, the temporary suspender method was used for conducting the suspender replacement in this study. 2 .

\section{Main Types of Damage in Suspenders}

The corrosion of the suspender system is mainly initiated by the failure of the protection system. After investigating and monitoring the bridge, it was found that the suspender system had missing and corroded bolts on the protection cover of the suspension rod anchor cup, corrosion of the anchor cup, water seepage, water accumulation, and corrosion of the joint between the protection cover and anchor box. This type of defect is likely to cause narrow cracks in the structure, resulting in easy infiltration of rainwater, and serious leakage is induced in the anchor cup along the boom. Moreover, it is difficult to remove or evaporate water, thereby causing the anchor head to rust.

The process of inspecting the suspender for internal corrosion can be described as follows: First, the waterproof cover at the lower part of the suspender is opened, the shock absorber is removed, and a small tool is used to clean the polyurethane foam adhesive inside the cable conduit. Then, an endoscope is used to observe the corrosion of the scattered steel strand in the external anchorage section of the anchor cable protection conduit. For the steel bundle that could not be examined with an endoscope, the corrosion inspection was conducted after making a small incision of $2 \mathrm{~cm}$ on the suspender protective sleeve, and it was found that some of the conduits had serious water accumulation. The water content of the polyurethane foam adhesive in the cable conduit was large, and when the foam adhesive was removed, the water dripped out and white mould was observed on the surface of some steel bundles. The corrosion state is illustrated in Figure 1. Certain types of damage in the anchorage are depicted in Figure 2.

\section{Project Overview}

The Beishengou bridge, shown in Figure 3, is a long-span suspender arch bridge, specifically a half-through concretefilled steel tubular arch bridge, spanning a deep ditch in a mountainous area with a main span of $260 \mathrm{~m}$. The carriageway beam is a $\pi$-shaped beam of reinforced concrete. The bridge construction utilised simple support followed by continuous construction technology. The elevation design of the bridge is depicted in Figure 4, and the layout of the main bridge structure is illustrated in Figure 5.

The width of the subgrade connected by the bridge is $23 \mathrm{~m}$, the arch axis of the main arch is catenary, the rise-span ratio is $1 / 4.5$, arch rib height is $5.5 \mathrm{~m}$, width is $2.9 \mathrm{~m}$, and the section form is of the truss type. The single-side arch rib is a truss arch rib made of four pieces of Q345 steel pipes of strength $\Phi 1000 \mathrm{~mm}$. The arch rib and the flat joint plate are 


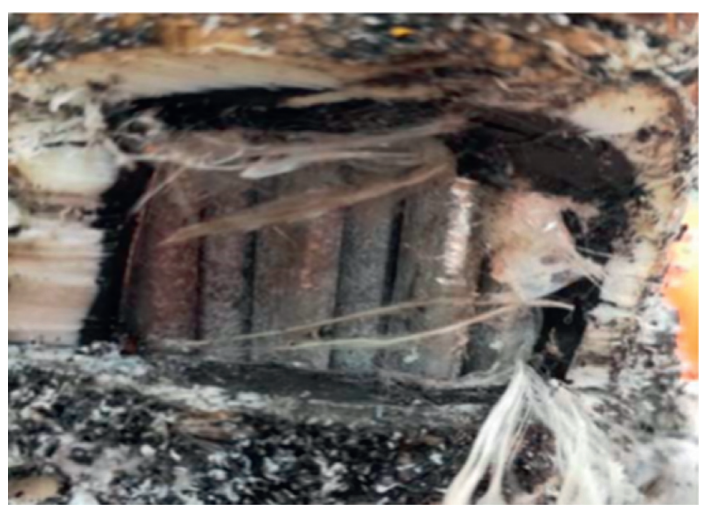

(a)

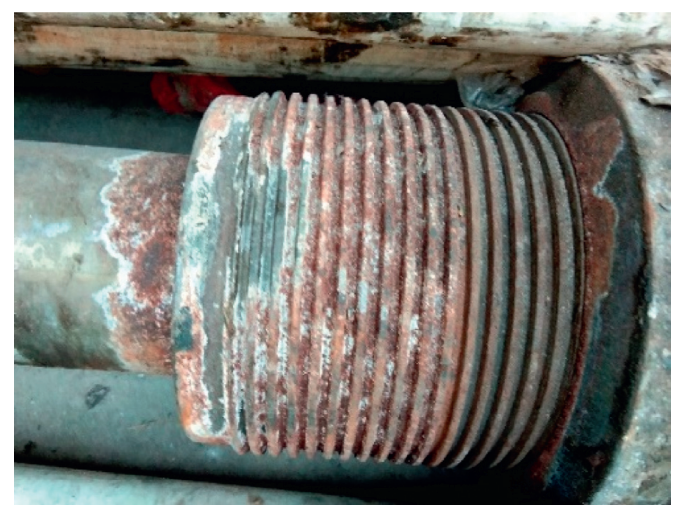

(b)

Figure 1: Corrosion inside the suspender: (a) corroded steel bundle; (b) corrosion in the anchor cup.

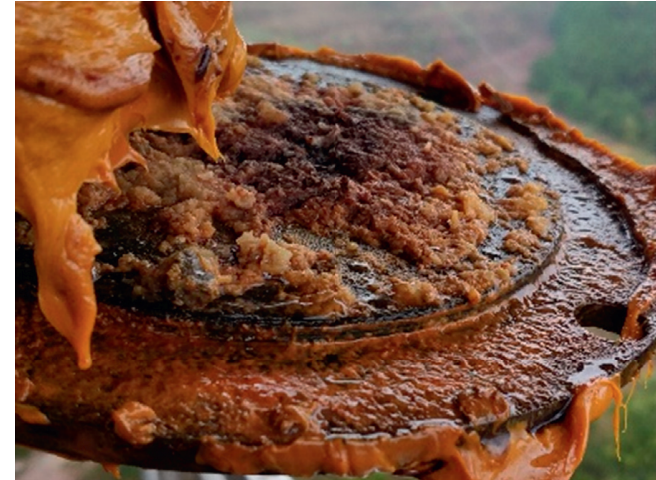

(a)

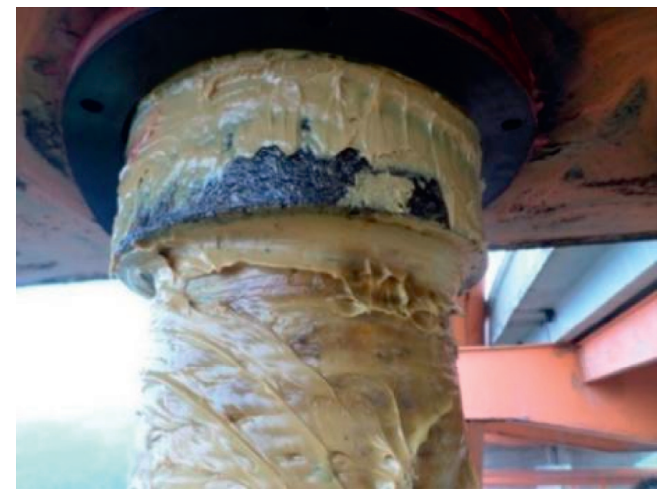

(c)

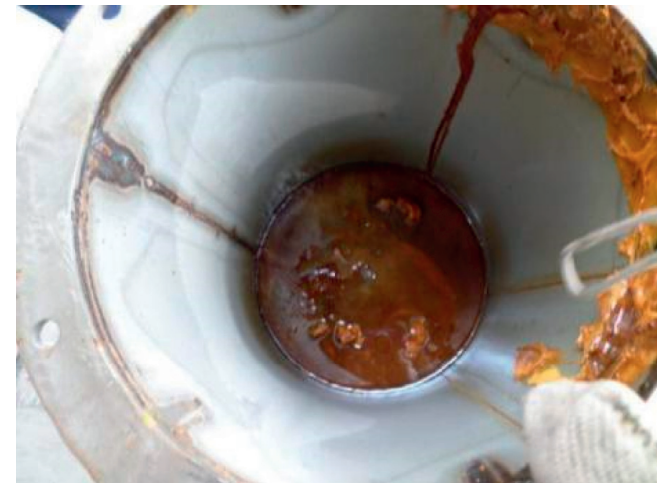

(b)

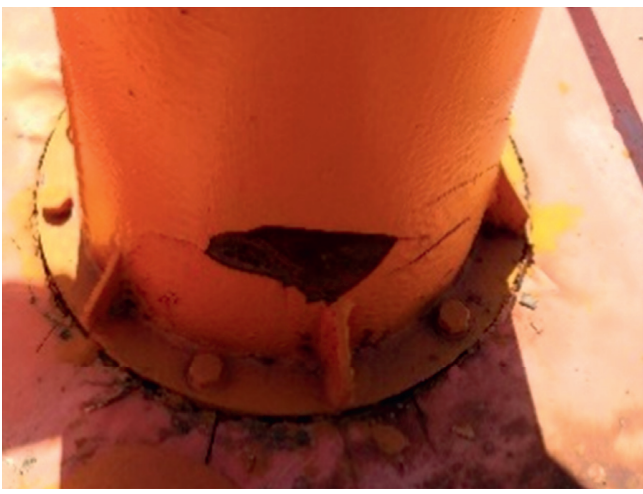

(d)

Figure 2: Anchorage damage: (a) water accumulation at the anchorage end; (b) water seepage of the anchor head; (c, d) corrosion of the anchor cup of the suspender.
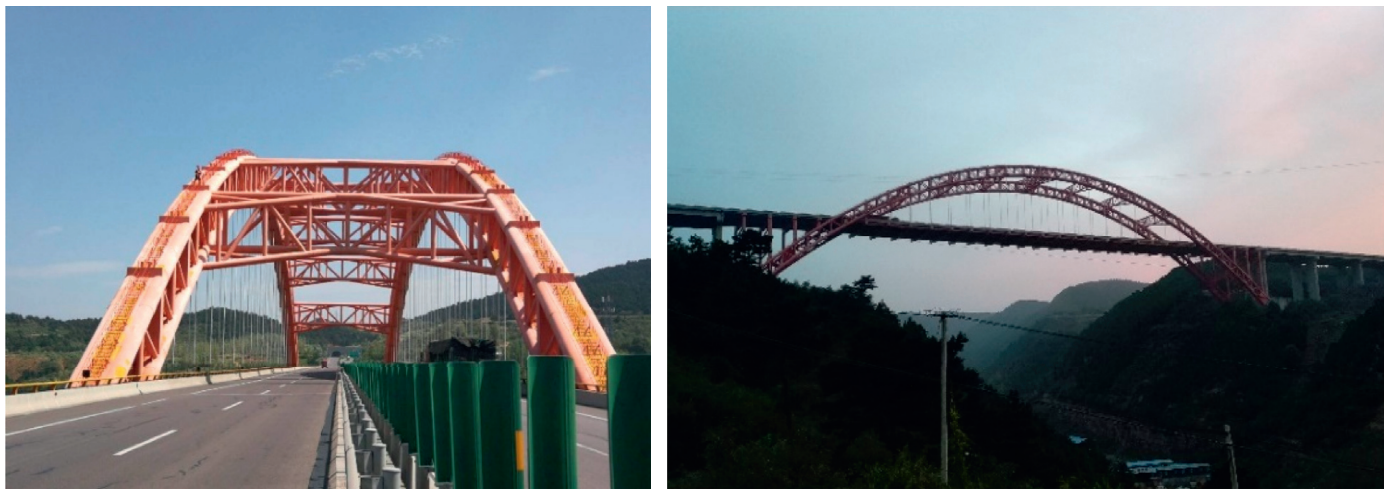

Figure 3: Beishengou concrete-filled steel tube arch bridge. 


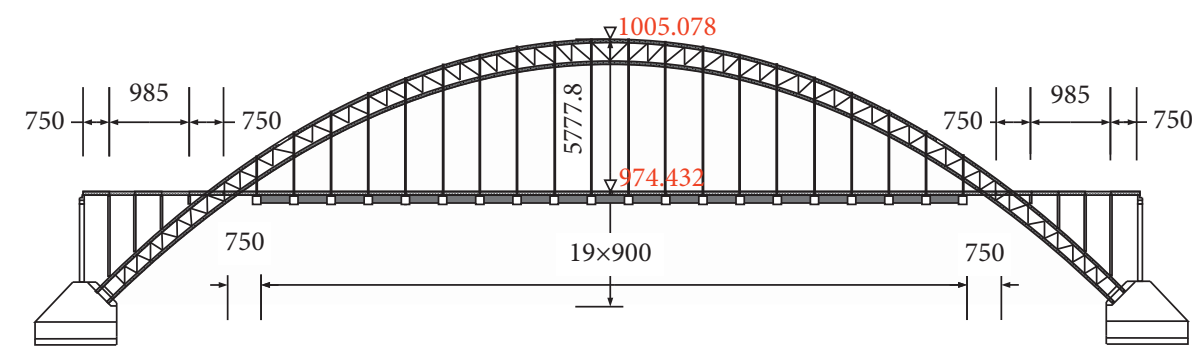

Figure 4: Bridge elevation structure drawing.

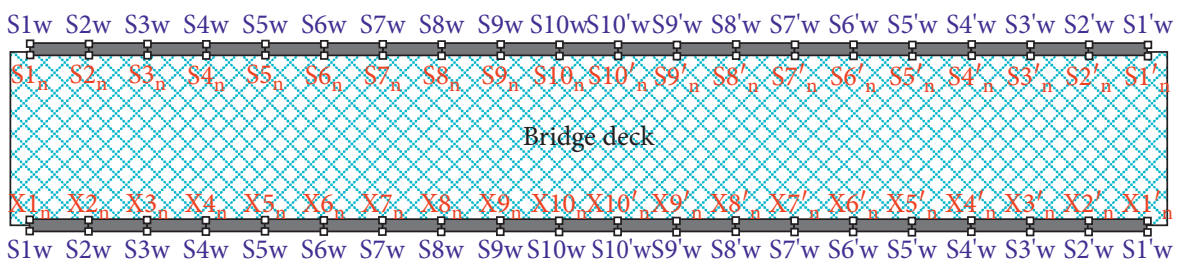

Figure 5: Schematic of arch bridge numbering.

covered in C50 micro-expansion concrete. The middle part is connected by a web member, which is a hollow steel pipe with the strength of Q345 steel. The suspenders on one side of the arch bridge are divided into inner and outer double suspenders totalling $2 \times 20$. Altogether, there are 80 suspenders on the entire bridge. The centre distance between the upstream and downstream suspenders is $25.7 \mathrm{~m}$. The upper end and arch rib are connected by the anchor box, and the lower end is anchored by a cold-cast anchor.

The bridge is constructed with single-side double suspenders. The letters $S$ and $X$ denote the upstream and downstream positions of the suspenders, and the notations $N$ and $W$ at the corner denote their internal and external positions. From the Yangcheng end, the suspenders from the side span to the middle span are numbered from No. 1 to No. 10 from the short to the long suspenders. The shortest label from the middle of the span to the closing end of the side span is No. $10^{\prime}-$ No. $1^{\prime}$; for example, No. $\mathrm{S} 2{ }_{n}$ indicates the second inner suspender measured from the Yangcheng end. The numbering sequence is depicted in Figure 5.

\section{Finite Element Model of the Bridge}

To clarify the suspender cable force during the operation period following the completion of the bridge, the finite element model of the bridge was established using Midas Civil software. The total number of bridge units is 5313, including 5344 beam units, 80 truss units, bridge-side guardrails, anti-collision guardrails, and bridge pavement, which are converted into a beam unit allocation eccentric load. The basic structure of the model is illustrated in Figure 6.

When the vehicle load passes through the bridge, the impact load of the vehicle can easily lead to fracture of the suspender sheath, which intensifies the stress fatigue corrosion of the suspender. In comparison with long suspenders, short suspenders are more prone to fatigue damage because they have greater rigidity and higher natural frequency, and the anchoring end is in a state of repeated bending and shearing for an extended period. Consequently, they are impacted to a greater extent by the vehicles and are more prone to cracking and damage. It can be seen from Tables 2 and 3 that under the action of the dead load and moving load of the arch bridge, the cable force of the suspender is larger at both ends and smaller in the middle, and the tension is evenly distributed. In other words, it can be inferred that the service state of the short suspender at the end of the bridge is poorer than that of the long derrick in the middle. Owing to the large difference in the effects of the load on the suspenders of different lengths, the service lives of the suspenders are different. The short suspender, as the short plate, directly determines the service life of the entire bridge. A commonly used method to increase the service life of the bridge is the regular replacement of the suspenders.

\section{Analysis of Suspender Replacement}

The temporary system is composed of a temporary suspender, upper and lower reaction beams, wedge-shaped support, reaction beam, connecting beam, and tensioning equipment. Among them, the temporary suspender and upper and lower reaction beams play the most significant role in the entire temporary transfer system. Before the replacement construction, the stress condition of these two parts should be fully considered.

6.1. Force Analysis of the Temporary Suspender. The original suspender is completely unloaded during the replacement process, and the temporary suspender bears the entire force on the unloaded suspender. Therefore, the temporary suspender must meet the bearing capacity requirements and have a sufficient safety factor. 


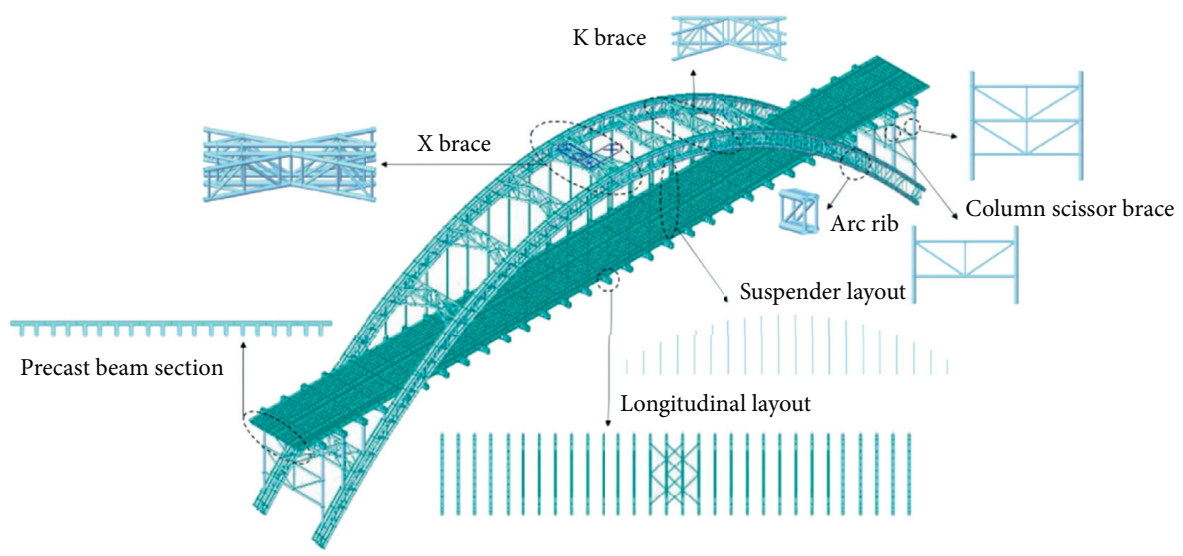

Figure 6: Finite element model of the bridge.

TABLE 2: Standard value of boom tension under dead load.

\begin{tabular}{|c|c|}
\hline Suspender no. & Cable force $(\mathrm{kN})$ \\
\hline $\mathrm{X} 1_{\mathrm{w}, \mathrm{n}}$ & 740.6 \\
\hline $\mathrm{X} 2_{\mathrm{w}, \mathrm{n}}$ & 720.3 \\
\hline $\mathrm{X} 3_{\mathrm{w}, \mathrm{n}}$ & 713.4 \\
\hline $\mathrm{X} 4_{\mathrm{w}, \mathrm{n}}$ & 716.9 \\
\hline $\mathrm{X} 5_{\mathrm{w}, \mathrm{n}}$ & 717.8 \\
\hline $\mathrm{X} 6_{\mathrm{w}, \mathrm{n}}$ & 718.0 \\
\hline $\mathrm{X} 7_{\mathrm{w}, \mathrm{n}}$ & 717.0 \\
\hline $\mathrm{X} 8_{\mathrm{w}, \mathrm{n}}$ & 718.3 \\
\hline $\mathrm{X} 9_{\mathrm{w}, \mathrm{n}}$ & 725.5 \\
\hline $\mathrm{X} 10_{\mathrm{w}, \mathrm{n}}$ & 735.6 \\
\hline $\mathrm{X} 10_{\mathrm{w}, \mathrm{n}}^{\prime}$ & 734.9 \\
\hline $\mathrm{X} 9_{\mathrm{w}, \mathrm{n}}^{\prime}$ & 725.7 \\
\hline $\mathrm{X} 8_{\mathrm{w}, \mathrm{n}}^{\prime}$ & 715.1 \\
\hline $\mathrm{X} 7_{\mathrm{w}, \mathrm{n}}^{\prime \prime, i n}$ & 718.6 \\
\hline $\mathrm{X} 6_{\mathrm{w}, \mathrm{n}}^{\prime}$ & 718.6 \\
\hline $\mathrm{X} 5_{\mathrm{w}, \mathrm{n}}^{\prime}$ & 717.7 \\
\hline $\mathrm{X} 4_{\mathrm{w}, \mathrm{n}}^{\prime,, 11}$ & 715.9 \\
\hline $\mathrm{X} 3_{\mathrm{w}, \mathrm{n}}^{\prime \prime n}$ & 716.3 \\
\hline $\mathrm{X} 2_{\mathrm{w}, \mathrm{n}}^{\prime}$ & 719.1 \\
\hline $\mathrm{X} 1_{\mathrm{w}, \mathrm{n}}^{\prime \prime, i n}$ & 740.0 \\
\hline $\mathrm{S} 1_{\mathrm{w}, \mathrm{n}}$ & 740.6 \\
\hline $\mathrm{S} 2_{\mathrm{w}, \mathrm{n}}$ & 720.3 \\
\hline$S 3_{\mathrm{w}, \mathrm{n}}$ & 713.4 \\
\hline $\mathrm{S} 4_{\mathrm{w}, \mathrm{n}}$ & 716.9 \\
\hline $\mathrm{S} 5_{\mathrm{w}, \mathrm{n}}$ & 717.8 \\
\hline $\mathrm{S} 6_{\mathrm{w}, \mathrm{n}}$ & 718.0 \\
\hline $\mathrm{S} 7_{\mathrm{w}, \mathrm{n}}$ & 717.0 \\
\hline $\mathrm{S} 8_{\mathrm{w}, \mathrm{n}}$ & 718.3 \\
\hline $\mathrm{S} 9_{\mathrm{w}, \mathrm{n}}$ & 725.5 \\
\hline $\mathrm{S} 10_{\mathrm{w}, \mathrm{n}}$ & 735.6 \\
\hline $\mathrm{S} 10_{\mathrm{w}, \mathrm{n}}^{\prime}$ & 734.9 \\
\hline $\mathrm{S} 9_{\mathrm{w}, \mathrm{n}}^{\prime}$ & 725.7 \\
\hline $\mathrm{S} 8_{\mathrm{w}, \mathrm{n}}^{\prime \prime n}$ & 715.1 \\
\hline$S 7_{\mathrm{w}, \mathrm{n}}^{\prime N, 11}$ & 718.6 \\
\hline $\mathrm{S} 6_{\mathrm{w}, \mathrm{n}}^{\prime \prime}$ & 718.6 \\
\hline $\mathrm{S} 5_{\mathrm{w}, \mathrm{n}}^{\mathrm{w}, \mathrm{n}}$ & 717.6 \\
\hline $\mathrm{S} 4_{\mathrm{w}, \mathrm{n}}^{\mathrm{N}, \mathrm{n}}$ & 715.9 \\
\hline $\mathrm{S} 3_{\mathrm{w}, \mathrm{n}}^{\prime \prime, 11}$ & 716.3 \\
\hline$S 2_{w, n}^{\prime N, 11}$ & 719.1 \\
\hline $\mathrm{S} 1_{\mathrm{w}, \mathrm{n}}^{\prime, 1 \mathrm{II}}$ & 740.0 \\
\hline
\end{tabular}

TABle 3: Standard value of boom tension under moving load.

\begin{tabular}{|c|c|}
\hline Suspender no. & Cable force $(\mathrm{kN})$ \\
\hline $\mathrm{X} 1_{\mathrm{w}, \mathrm{n}}$ & 278.1 \\
\hline $\mathrm{X} 2_{\mathrm{w}, \mathrm{n}}$ & 253.1 \\
\hline $\mathrm{X} 3_{\mathrm{w}, \mathrm{n}}$ & 227.4 \\
\hline $\mathrm{X} 4_{\mathrm{w}, \mathrm{n}}$ & 224.0 \\
\hline $\mathrm{X} 5_{\mathrm{w}, \mathrm{n}}$ & 219.6 \\
\hline $\mathrm{X} 6_{\mathrm{w}, \mathrm{n}}$ & 216.2 \\
\hline $\mathrm{X} 7_{\mathrm{w}, \mathrm{n}}$ & 213.7 \\
\hline $\mathrm{X} 8_{\mathrm{w}, \mathrm{n}}$ & 211.8 \\
\hline $\mathrm{X} 9_{\mathrm{w}, \mathrm{n}}$ & 208.7 \\
\hline $\mathrm{X} 10_{\mathrm{w}, \mathrm{n}}$ & 203.5 \\
\hline $\mathrm{X} 10_{\mathrm{w}, \mathrm{n}}^{\prime}$ & 203.5 \\
\hline $\mathrm{X} 9_{\mathrm{w}, \mathrm{n}}^{\prime}$ & 208.7 \\
\hline $\mathrm{X} 8_{\mathrm{w}, \mathrm{n}}^{\prime}$ & 211.8 \\
\hline $\mathrm{X} 7_{\mathrm{w}, \mathrm{n}}^{\prime \prime, i t}$ & 213.7 \\
\hline $\mathrm{X} 6_{\mathrm{w}, \mathrm{n}}^{\prime}$ & 216.2 \\
\hline $\mathrm{X} 5_{\mathrm{w}, \mathrm{n}}^{\prime}$ & 219.6 \\
\hline $\mathrm{X} 4_{\mathrm{w}, \mathrm{n}}^{\prime, \mathrm{n}}$ & 224.0 \\
\hline $\mathrm{X} 3_{\mathrm{w}, \mathrm{n}}^{\prime \prime, n}$ & 227.4 \\
\hline $\mathrm{X} 2_{\mathrm{w}, \mathrm{n}}^{\prime \prime, 11}$ & 253.1 \\
\hline $\mathrm{X} 1_{\mathrm{w}, \mathrm{n}}^{\prime, \mathrm{n}}$ & 278.1 \\
\hline $\mathrm{S} 1_{\mathrm{w}, \mathrm{n}}$ & 332.5 \\
\hline $\mathrm{S} 2_{\mathrm{w}, \mathrm{n}}$ & 302.6 \\
\hline$S 3_{w, n}$ & 271.5 \\
\hline$S 4_{\mathrm{w}, \mathrm{n}}$ & 267.0 \\
\hline $\mathrm{S} 5_{\mathrm{w}, \mathrm{n}}$ & 261.5 \\
\hline $\mathrm{S} 6_{\mathrm{w}, \mathrm{n}}$ & 257.2 \\
\hline$S 7_{\mathrm{w}, \mathrm{n}}$ & 254.1 \\
\hline $\mathrm{S} 8_{\mathrm{w}, \mathrm{n}}$ & 251.8 \\
\hline $\mathrm{S} 9_{\mathrm{w}, \mathrm{n}}$ & 248.1 \\
\hline $\mathrm{S} 10_{\mathrm{w}, \mathrm{n}}$ & 242.0 \\
\hline $\mathrm{S} 10_{\mathrm{w}, \mathrm{n}}^{\prime}$ & 242.0 \\
\hline $\mathrm{S} 9_{\mathrm{w}, \mathrm{n}}^{\prime \mathrm{w}, 1}$ & 248.1 \\
\hline $\mathrm{S} 8_{\mathrm{w}, \mathrm{n}}^{\prime, \mathrm{n}}$ & 251.8 \\
\hline $\mathrm{S} 7_{\mathrm{w}, \mathrm{n}}^{\mathrm{w}, \mathrm{n}}$ & 254.1 \\
\hline $\mathrm{S} 6_{\mathrm{w}, \mathrm{n}}^{\prime}$ & 257.2 \\
\hline $\mathrm{S} 5_{\mathrm{w}, \mathrm{n}}^{\prime \prime N, 1}$ & 261.5 \\
\hline $\mathrm{S} 4_{\mathrm{w}, \mathrm{n}}^{\mathrm{w}, \mathrm{n}}$ & 267.0 \\
\hline $\mathrm{S} 3_{\mathrm{w}, \mathrm{n}}^{\prime \prime N}$ & 271.5 \\
\hline $\mathrm{S} 2_{\mathrm{w}, \mathrm{n}}^{\prime \prime n}$ & 302.6 \\
\hline $\mathrm{S} 1_{\mathrm{w}, \mathrm{n}}^{\prime, \mathrm{N}}$ & 332.5 \\
\hline
\end{tabular}


According to the requirements of the design drawing, the reliability of the temporary suspender was calculated. The temporary suspender undertakes the task of the suspender during the process of cable replacement. The calculation was conducted on the No. S3 and No. S4 suspenders of the PESC7-73 model with a large cable force. The cable force of the No. S3 suspender was $774.1 \mathrm{kN}$ and that of the S4 suspender was $739.6 \mathrm{kN}$, totalling a value of $1513.7 \mathrm{kN}$.

In this project, $12 \times 4$ groups $=48$ steel strands with a diameter of $15.24 \mathrm{~mm}$ and strength of $1860 \mathrm{MPa}$ were used as the temporary suspenders. The force calculation is explained below.

The ultimate bearing capacity of 48 steel strand suspenders is obtained as follows:

$$
48 \times A \times 1860=48 \times 140 \times 1860=12499.2 \mathrm{kN} .
$$

Safety factor:

$$
K=\frac{12499.2 \mathrm{kN}}{1513.7 \mathrm{kN}}=8.25 \geq 2 .
$$

The bearing capacity of the temporary suspender satisfied the above requirements.

6.2. Force Analysis of the Reaction Beam. The role of the reaction beam is to fix the temporary suspender and transfer the force on the suspender to the arch rib and beam. In the actual project, the Q345D steel was processed into the steel beam form; the dimensions of the structure are depicted in Figure 7.

The main body of a single reaction beam is an I-shaped beam welded with double-channel steel. The overall stiffness is increased by the connecting plate and stiffening plate, and the rubber plate is used as a buffer. To simplify the calculation, the effects of the stiffening plate and rubber plate were not considered in the structural mechanics calculation of the reaction beam. The materials used are presented in Table 4. The maximum value of the concentrated force was $P \max =187.5 \mathrm{kN}$ and its minimum value was $P \min =182.5 \mathrm{kN}$. The point of calculation is the tension position of the temporary suspender. Considering the most unfavourable situation, the concentrated force was directly taken as $P=P \max =187.5 \mathrm{kN}$.

The upper reaction beam is connected with the arch rib through the wedge support block installed on the arch rib. The simplified diagram is illustrated in Figure 8. The boundary condition was set as consolidation, and the node load was set at the tension position of the temporary suspender. Figure 9 depicts the internal shear force, bending moment, and displacement of the upper reaction beam when a single temporary suspender is tensioned to the maximum control stress. The length of the upper reaction beam is large, but the maximum displacement of the beam end caused by the deformation is less than $0.5 \mathrm{~mm}$, which can be ignored.

The point where the cross-beam supports the lower reaction beam is on the rubber plate contact surface between the lower reaction beam and the cross-beam. However, because the lower reaction beam is not allowed to have lateral displacement and rotation during the construction process, and the boundary conditions are set as consolidation, the distance between the two points represents the width of a single beam. The node load was set at the tension position of the temporary hanger rod, which was simplified as depicted in Figure 10. Figure 11 shows the internal shear force, bending moment, and displacement of the lower reaction beam when a single temporary suspender is tensioned to the maximum control stress.

The maximum displacement point of the lower reaction beam is also at the beam end, which is $0.17168 \mathrm{~mm}$. However, the existence of the connecting beam of the lower reaction beam in the actual construction places a certain constraint on the beam end and further improves the overall stiffness; therefore, the actual displacement of the lower reaction beam is smaller than the model value.

\subsection{Construction Preparation for Suspender Replacement}

(1) Owing to the large number of suspenders and large span of the arch bridge, to reasonably reduce unnecessary workload and shorten the duration of influence on traffic, the main girder section corresponding to suspender Nos. S1, S2, S3, S4, and S5 was selected as the target section. Two measurement points were arranged horizontally, upstream and downstream. Each point was located $5 \mathrm{~cm}$ inside the anti-collision wall. There were 10 measurement points on the bridge deck alignment, as depicted in Figures 12 and 13.

Three days before the construction, the ambient temperature was recorded under moving traffic. According to the proposed construction start time, the high-precision total station was used to measure the bridge deck alignment once every hour within $\pm 3 \mathrm{~h}$; according to the proposed construction end time, the bridge deck alignment measurement was conducted once every hour within $\pm 3 \mathrm{~h}$. The measurement results were used as reference for linear control in the suspender replacement construction.

(2) The current cable length was calculated according to the measured space coordinates between the upper and lower anchor plates of each suspender, and the result was compared with the values in the original design drawings as the basis for the length of the new suspender. The degree of damage of the suspender protection system, degree of damage of the cable body, degree of corrosion of the anchorage system, and fracture status of the specific parts and steel wire were recorded as the basis for the maintenance of the suspender in the future.

The original bridge uses OVMLZM-I type parallel steel wire cold casting anchor system with $\Phi 7 \mathrm{~mm}$ steel wire as the main load-bearing bar; the steel 


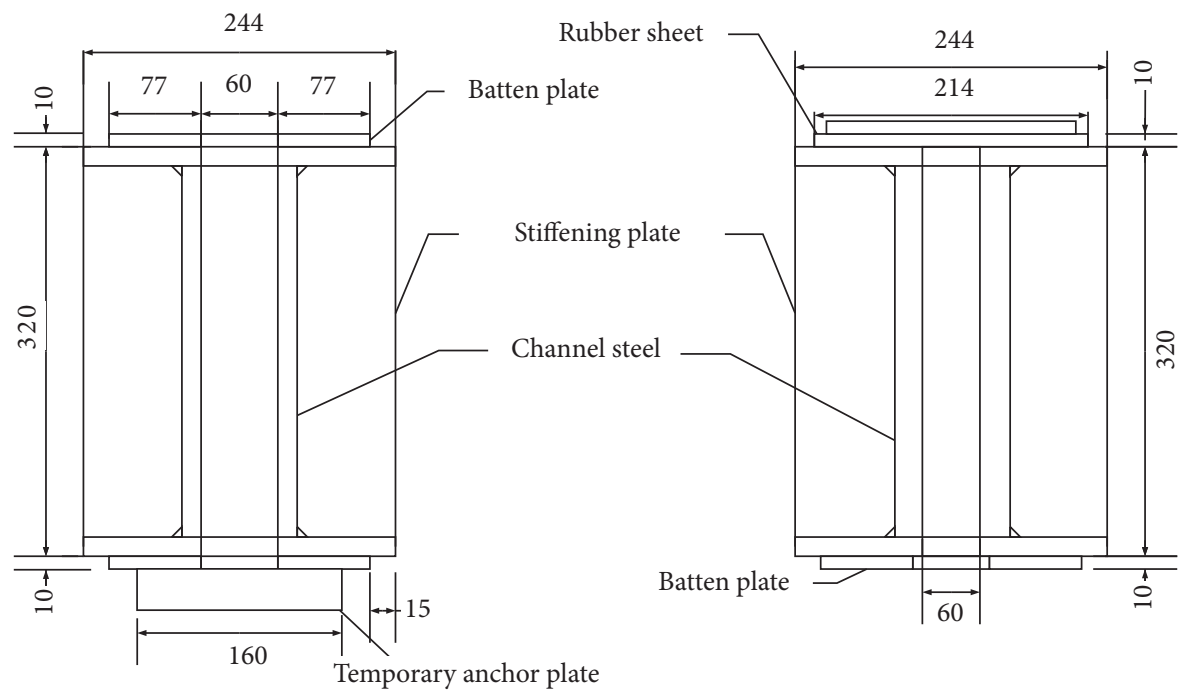

FIGURE 7: Cross section of lower reaction beam.

TABLE 4: Materials used in the single reaction beam.

\begin{tabular}{lccc}
\hline Number & Name & Material & Specification \\
\hline N1 & Channel steel & Q345D & $32 \mathrm{c} \times 1444$ \\
N2 & Connection plate & Q345D & $214 \times 10 \times 1444$ \\
N3 & Stiffening plate & Q345D & $292 \times 10 \times 80$ \\
N4 & Rubber sheet & - & $200 \times 10 \times 200$ \\
\hline
\end{tabular}

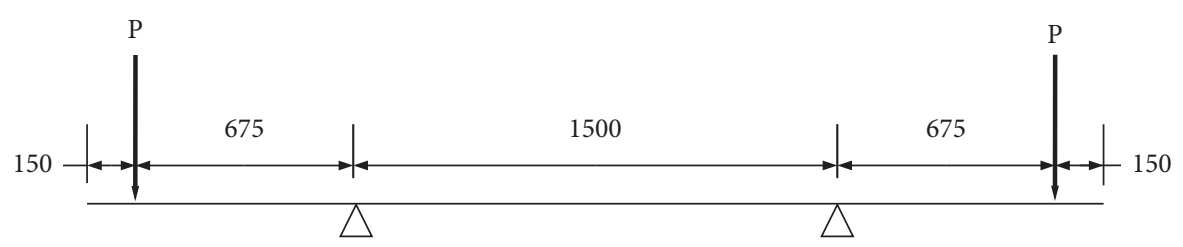

FIgURE 8: Force diagram of the upper reaction beam.

strength is $1670 \mathrm{MPa}$. Its structure system mainly consists of dozens of parallel steel wires wrapped with polyurethane tape and then with an HDPE protective layer. To ensure the unity of the structure types of the new and old booms after the replacement of the defective suspenders, the OVMLZM-I type parallel steel wire cold-cast anchor system boom was used as the new boom. In addition, the cable force was measured, and the cable force value of each suspender before the replacement was recorded.

(3) In order to facilitate the site layout, the construction operation platform for the suspender replacement was built after restricting the traffic flow. The system mainly included the operation platform on the main arch rib for the removal of the old suspender and installation of a new suspender, and the operation platform at the lower end of the suspender for the installation of the anchor head and tensioning equipment.
(4) The installation of the temporary suspender system mainly involved a temporary suspender, upper and lower bearing beams, wedge-shaped support, and tensioning equipment, as depicted in Figures 14-17.

In the suspender force conversion, a wedge-shaped support was installed on the arch rib in advance. The steel beam was symmetrically arranged on the anchor head side on the top surface of the arch rib to be replaced. A Jack and temporary steel strand sling system were installed on each beam. Two steel support beams were arranged at the bottom of the beam under the bridge and connected with the temporary steel strand suspender.

To ensure safety, the temporary suspender anchorage adopted a special low-stress anti-loosening anchorage. The tensioning Jack was equipped with a hydraulic self-locking valve, and a mechanical safety anchorage system was set on the cross-beam to ensure that the force of the temporary suspender was not affected under failure of the oil circuit of the Jack, and the force transfer process between the suspenders was stable. 


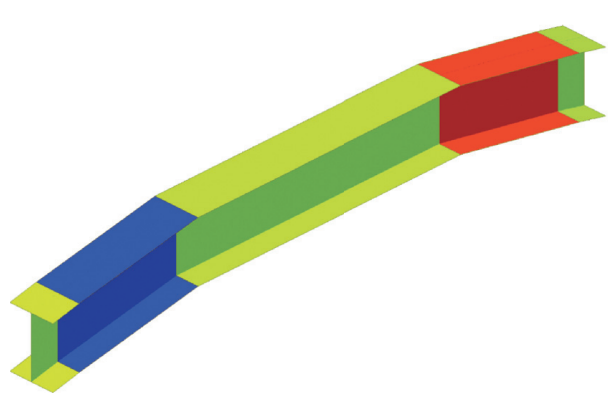

(a)
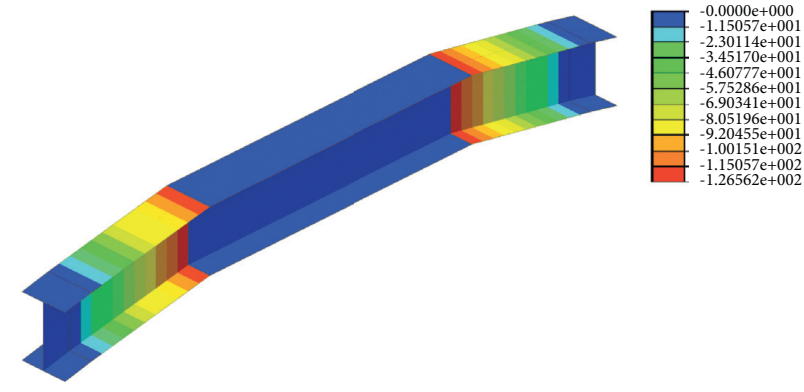

(b)
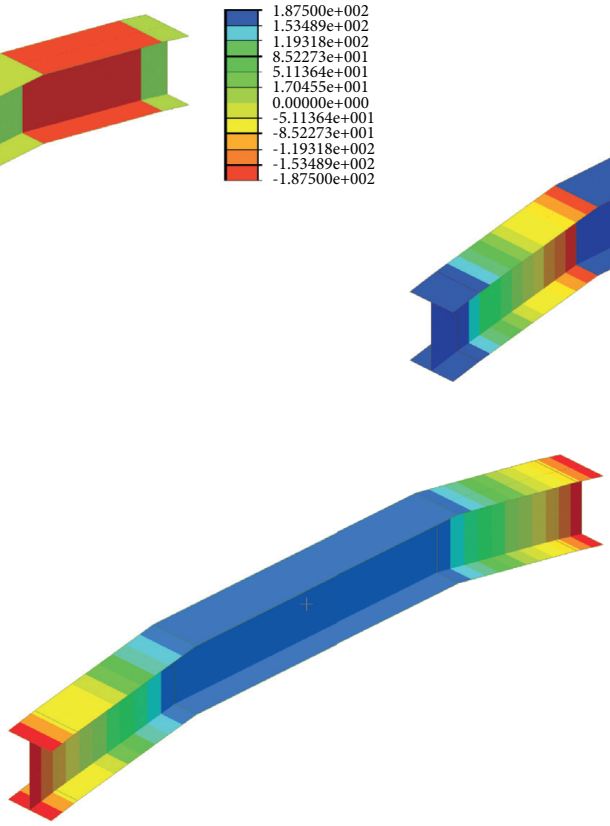

(c)

FIGURE 9: State of the upper reaction beam: (a) bending moment diagram of the lower reaction beam; (b) shear diagram of the lower reaction beam; (c) displacement diagram of the lower reaction beam.

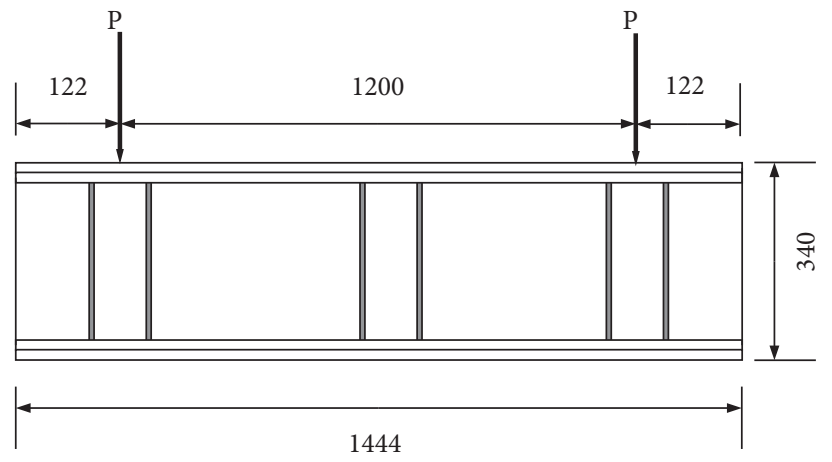

FIgURE 10: Cross section of the lower reaction beam.

\section{Suspender Replacement Construction Process}

7.1. Unloading of the Original Suspender. The first step in the suspender replacement process was to transfer the tension to the temporary suspenders. The old suspenders were cut off in batches and the cable forces were unloaded in stages to transfer them to the temporary suspenders.

The design value of the boom force was divided into four levels with unequal step lengths (the internal force of the first loading was $10 \%$ of the total internal force, and the internal force of the remaining three loadings were $30 \%$ of the total internal force), as presented in Table 5. The unloading of the cable force and the tension of the temporary suspender system should be carried out alternately to avoid significant changes in the bridge deck alignment. The change in the bridge deck elevation must be controlled within the range of
-3 to $+3 \mathrm{~mm}$, which should be applied to the temporary suspender gradually, and the original suspender should be removed.

In the entire process of cable force conversion, it is necessary to ensure that the temporary suspender system works properly without instability and damage to the original structure. In addition, restricted by the cable force transmission efficiency of the suspender, the tension force of the temporary boom system is greater than the unloading cable force of the original suspender. Therefore, we should focus on the monitoring of the cable force and the linear movement of the measuring points, and flexibly determine the adjustment of the cable force to prevent the bridge deck from sinking excessively.

7.2. Installation of New Suspender. The new suspender was installed after cleaning the embedded pipe and repairing the anchor plate. When hoisting the new suspender, the embedded pipe of the steel pipe arch was penetrated from bottom to top, and the suspender cable was placed at the centre of the embedded pipe to prevent scratch damage. After installing the correction device, the upper and lower anchoring ends were adjusted according to the construction design drawings. In addition, after installing the tensioning equipment, the new suspender in the middle was adjusted to prepare for tensioning.

7.3. Loading of the New Suspender. After the new suspender was installed in place, the suspender cable force was applied in a timely manner through gradual loading. First, the new suspender was applied with approximately $10 \%$ of the 


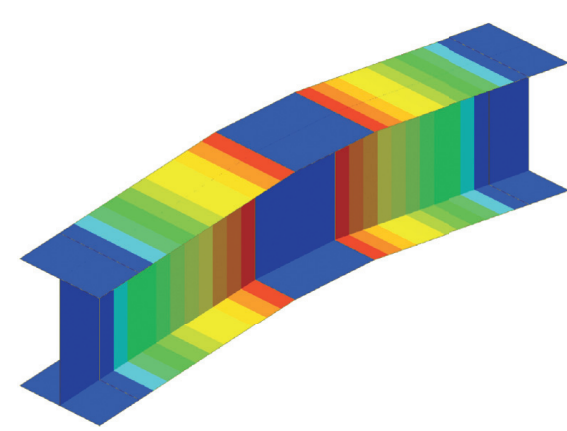

(a)

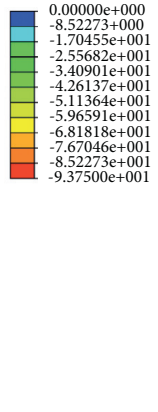

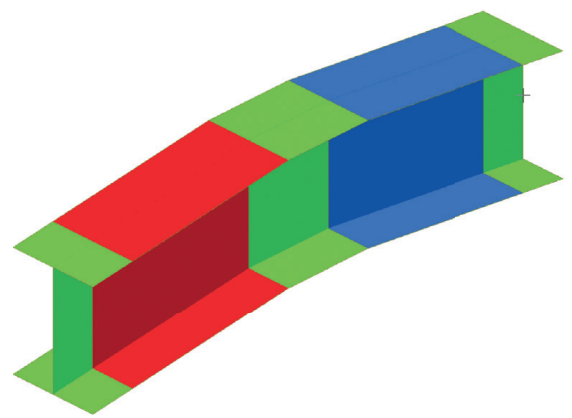

(b)
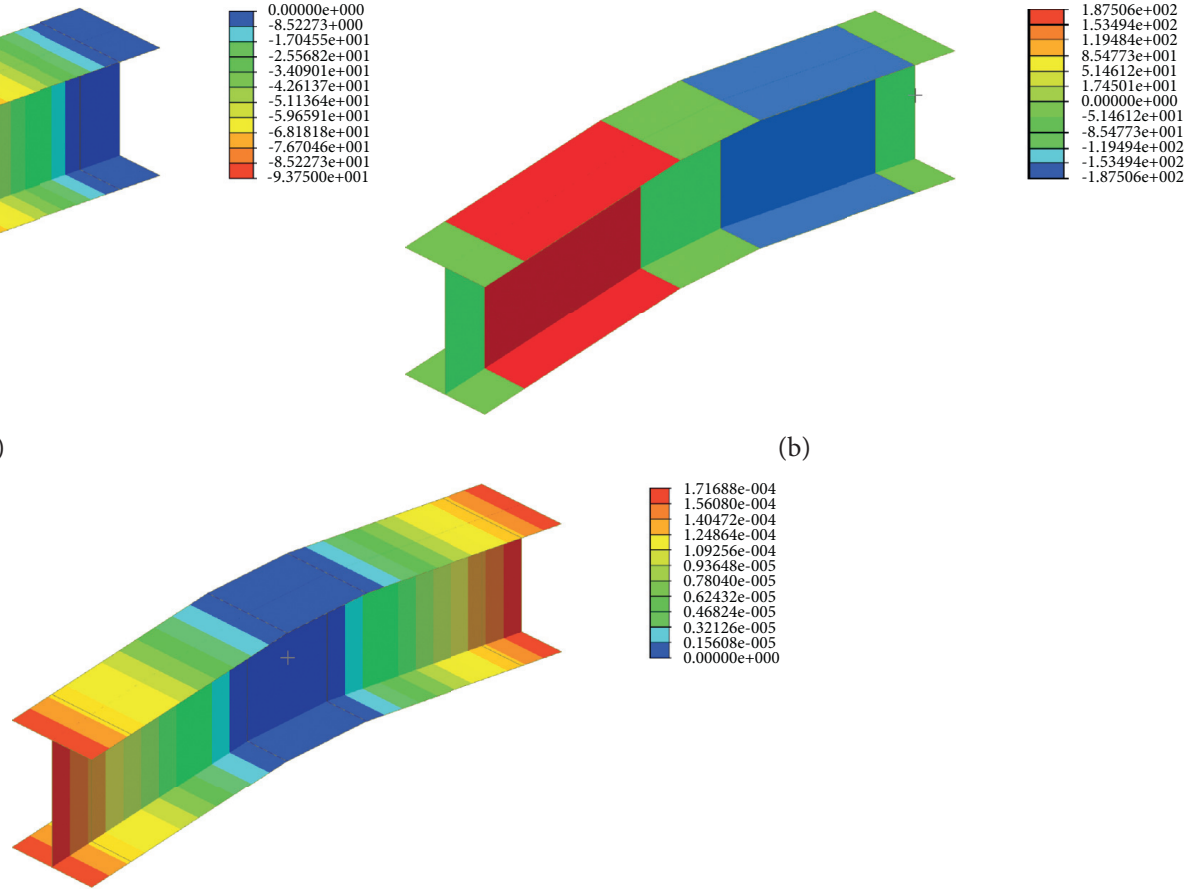

(c)

Figure 11: State of the lower reaction beam: (a) bending moment diagram of the lower reaction beam; (b) shear diagram of the lower reaction beam; (c) displacement diagram of the lower reaction beam.

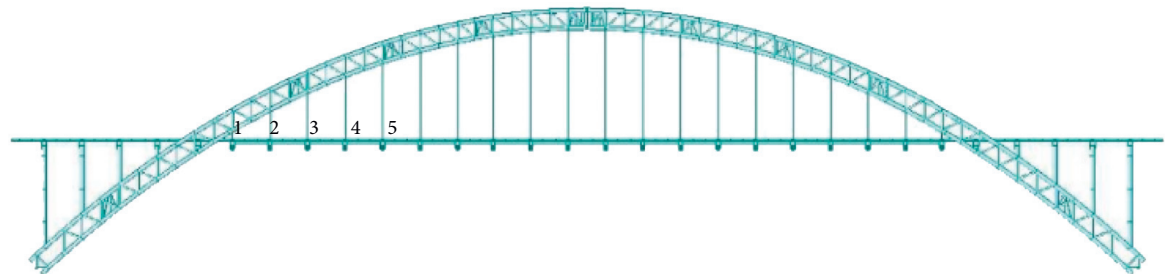

FIGURE 12: Side-view of the layout of alignment measurement points of the bridge deck.

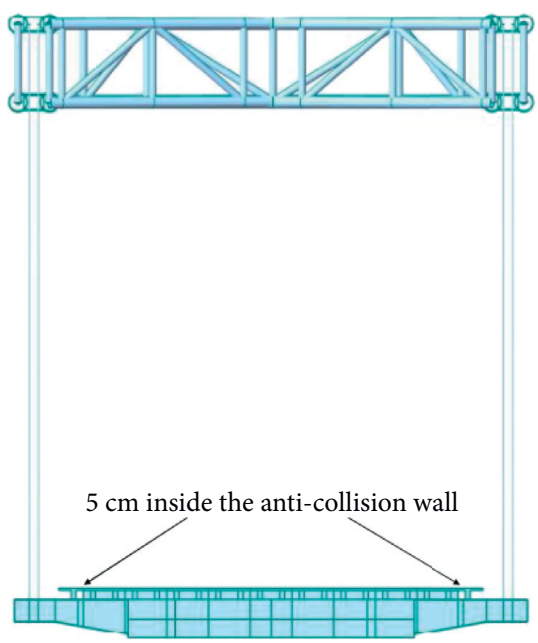

Figure 13: Front-view of the layout of alignment measurement points of the bridge deck. 


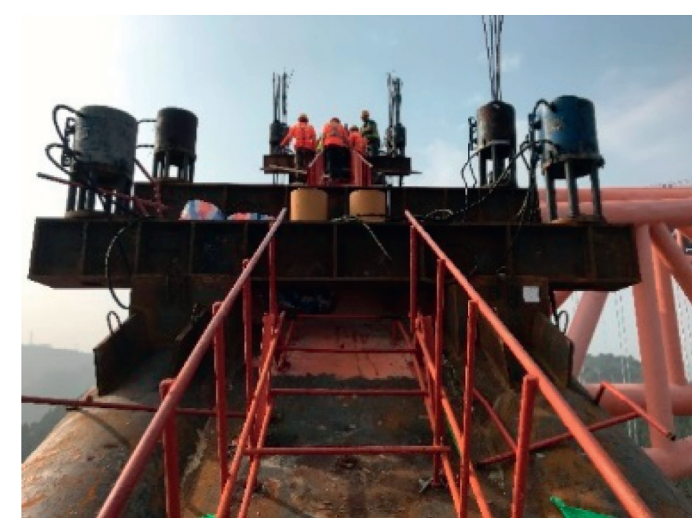

FIgURE 14: Temporary system above the arch rib.

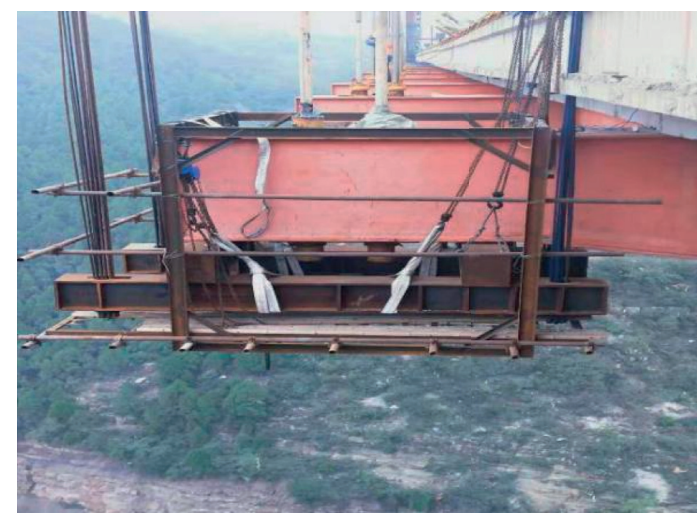

FIGURE 15: Lower reaction beam.

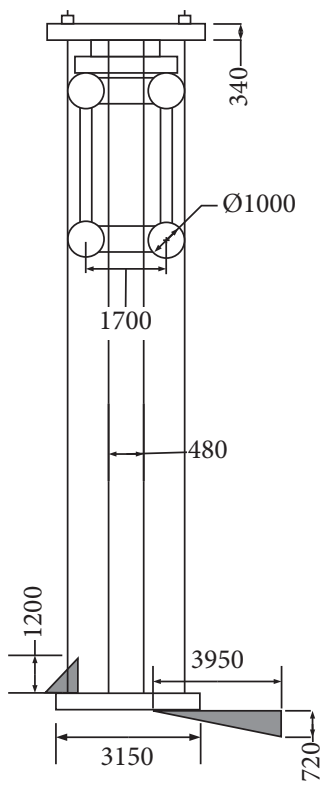

FIgURE 16: Elevation of the temporary suspender system.

suspender force to make it taut and provide a certain initial stress. Then, the remaining suspender force was divided into three levels; the temporary suspender was gradually relaxed

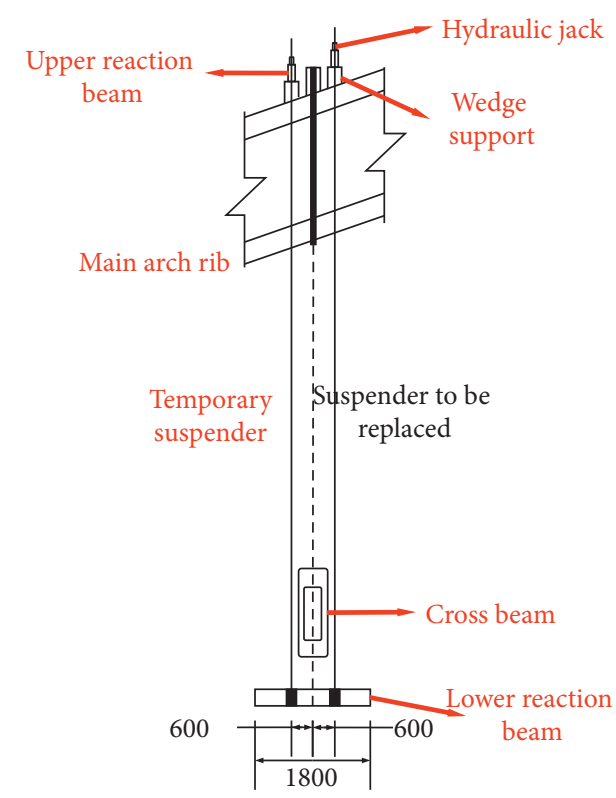

Figure 17: Profile of the temporary suspender system.

by the Jack, and the new suspender was tensioned step by step, as presented in Table 6.

Similarly, in the entire tensioning process of the new suspenders, the cable force should be tracked and monitored and the alignment of the measurement points should be checked to determine whether or not the cable force needs to be adjusted. After tensioning to the design tonnage and applying a proper elevation adjustment, the nuts and lock nuts were tightened, and the tensioning equipment was removed. The lower anchor head of the suspender was sealed with a stainless-steel protective cover, which was fixed on the beam by using anchor bolts. The lower end was waterproof and sealed to prevent water seepage. The anticorrosion material was poured into the embedded protective pipe at the lower end. After the gap in the anchor head was entirely filled, the upper and lower shock absorbers were installed.

The anticorrosion of the anchor head was enabled by coating a high-temperature nonflowing grease on the surface and installing a protective cover outside. After all suspenders were replaced, the suspender cable force and bridge deck elevation were measured and compared with the design control value. If the measured value exceeds the control value, the adjustment measures are assessed as early as possible and cyclic adjustments are applied until the suspender cable force and the shape of the bridge deck line are consistent with the original design.

\section{Principle of Measuring Suspender Cable Force Using Frequency Method}

In the process of suspender replacement, the natural frequency of the suspender is determined by disregarding the influence of the transverse bending stiffness of the suspender on the cable force calculation. According to the string vibration theory, the relationship between the suspender cable force and its natural frequency is as follows: 
TABLE 5: Conversion relationship between old suspender cable force and temporary suspender during unloading.

\begin{tabular}{lccccc}
\hline Step no. & $\begin{array}{c}\text { Cable force of old } \\
\text { suspender (\%) }\end{array}$ & $\begin{array}{c}\text { Temporary suspender } \\
1(\%)\end{array}$ & $\begin{array}{c}\text { Temporary suspender } \\
2(\%)\end{array}$ & $\begin{array}{c}\text { Temporary suspender } \\
3(\%)\end{array}$ & $\begin{array}{c}\text { Temporary suspender } \\
4(\%)\end{array}$ \\
\hline 1 & 100 & 0 & 0 & 0 & 0 \\
2 & 90 & 2.5 & 2.5 & 2.5 & 2.5 \\
3 & 60 & 10 & 10 & 17.5 & 10 \\
4 & 30 & 17.5 & 17.5 & 25 & 25 \\
5 & 0 & 25 & 25 & 5.5 & 25 \\
\hline
\end{tabular}

TABLE 6: Conversion relationship between new suspender cable force and temporary suspender under loading.

\begin{tabular}{lccccc}
\hline Step no. & $\begin{array}{c}\text { Cable force of old } \\
\text { suspender (\%) }\end{array}$ & $\begin{array}{c}\text { Temporary suspender } \\
1(\%)\end{array}$ & $\begin{array}{c}\text { Temporary suspender } \\
2(\%)\end{array}$ & $\begin{array}{c}\text { Temporary suspender } \\
3(\%)\end{array}$ & $\begin{array}{c}\text { Temporary suspender } \\
4(\%)\end{array}$ \\
\hline 1 & 0 & 25 & 25 & 25 & 25 \\
2 & 10 & 22.5 & 22.5 & 15 & 2.5 \\
3 & 40 & 15 & 15 & 7.5 & 7.5 \\
4 & 70 & 7.5 & 7.5 & 0 & 0 \\
5 & 100 & 0 & 0 & 0 \\
\hline
\end{tabular}

$$
T=4 \rho L^{2}\left(\frac{f_{n}}{n}\right)^{2},
$$

where $\rho$ denotes the linear density of the suspender; $L$ denotes the effective length of the suspender; $f_{n}$ denotes the $n$ th-order natural frequency of the suspender; $T$ denotes the suspender cable force; and $n$ denotes the natural vibration frequency order of the suspender.

By assigning $K=4 \rho L^{2}, f=f_{n} / n$, we obtain

$$
T=K f^{2} \text {. }
$$

Assuming that the cable force of a suspender is constant after tensioning, the cable force $T_{Q}$ of the suspender can be converted to the Jack calibration equation by substituting the oil gauge reading of the Jack when the suspender is anchored. When the first-order natural frequency of the suspender is used to calculate its cable force, the calibration formula of the proportion coefficient of the suspender cable force is

$$
K_{B}=\frac{T_{Q}}{f^{2}}
$$

where $T_{Q}$ denotes the suspender cable force obtained from the oil gauge reading of the Jack, that is, the Jack tension force in the calibration stage; $f_{1}$ denotes the first natural vibration frequency of the suspender, collected by the cable force dynamic tester after the suspender is tensioned. To eliminate the influence of the tensioning equipment on the identification of the natural frequency of the suspender, the first natural vibration frequency of the suspender is collected after the completion of the process of adding the tension to the suspender, after the removal of the tensioning equipment, and before the tensioning of the other suspenders. $K_{B}$ is the scale coefficient of the suspender cable force. Without considering the influence of the lateral bending stiffness of the suspender on the cable force test conducted, the calculation formula of the suspender cable force is as follows:

$$
T=K_{B} f^{2} .
$$

After the completion of the process of adding the suspender tension, the first-order natural frequency of each suspender is collected and substituted into equation (6) to calculate the cable force value of each suspender at this stage, which is used as the basis for the first adjustment of the cable. After removing the tie beam support and bridge deck pavement, the cable dynamic measurement instrument is used to collect the first-order natural frequency of each suspender. The same method can be used to obtain the suspender cable force for the full bridge. When the deviation between the measured cable force and the design value exceeds the specification requirements, the cable must be adjusted again.

Because the average treatment method is adopted, when $T$ is constant for a given suspender, $\left(f_{n} / n\right)^{2}$ is a constant value, and the following relationship exists between the frequencies of each order:

$$
\left(\frac{f_{1}}{1}\right)^{2}=\left(\frac{f_{2}}{2}\right)^{2}=\left(\frac{f_{3}}{3}\right)^{2}=\cdots=\left(\frac{f_{n}}{n}\right)^{2} .
$$

The frequencies are denoted as

$$
f_{1}: f_{2}: f_{3}: \cdots: f_{n}=1: 2: 3: \cdots: n .
$$

Therefore,

$$
f_{1}=f_{2}-f_{1}=f_{3}-f_{2}=\cdots=\frac{f_{n}}{n} .
$$

As reflected in the linear spectrum, successive orders of the frequency are equidistant, and the distance between them is equal to the fundamental frequency; thus, the fundamental frequency $\left(f_{1}\right)$ of the tested suspender can be obtained. 


\section{Measurement Methods and Results}

To avoid the influence of a change in environmental temperature on the cable force measurement, the measurement was conducted from 5:00 to 8:00 in the morning when there were no significant changes in the temperature. After the measuring instrument was firmly bound to the bridge deck at $L / 4$ of the length of the suspender by lifting the engineering vehicle, the suspender was excited. The excitation signal was transmitted and stored in the computer through the corresponding sensor. The arrangement is illustrated in Figure 18.

Owing to the influence of the anchor box at the anchor port of the suspender and upper and lower conduits, the calculated value $L_{0}$ of the suspender length should be corrected for the total length of the suspender. A common method is to subtract the total length of the conduit, and only consider the middle part as the approximate calculation length, which is input into the software for evaluation. The suspender structure is illustrated in Figure 19.

There are three types of built-in connection modes in the cable force calculation software, namely, both ends are hinged; one end is hinged, one end is fixed; and both ends are fixed. It is worth noting that the connection mode in the software cannot accurately reflect the actual connection situation, because the software calculation cannot calculate the frequency cable force under all conditions, which is equivalent to the "blind area" for users. It is necessary to estimate the approximate range of reasonable cable force in advance, and then consider the boundary conditions as the only variables in the field. Finally, the calculation results are screened for a given height of the same suspender.

The vibration signal waveform of the suspender contains the vibration information of the suspender and other loads during the test; therefore, it is necessary to identify and filter the original waveform. It is difficult to avoid environmental interference in signal acquisition. The interference of random vibration can be reduced by displaying the wave in advance and acquiring the waveform when it is stable. To ensure the accuracy of data measurement, the vibration frequencies of the first five orders should be read as accurately as possible in the data acquisition. The representative vibration spectrum of the suspender is selected as depicted in Figure 20

\section{Common Calculation Methods in Engineering}

The general calculation methods currently used in engineering are listed in Table 7. Among them, the T1 model assumes that both ends of the suspender are connected and considers the influence of section stiffness. The T2 model assumes that both ends of the suspender are consolidated and considers the influence of section stiffness. The other calculation methods are derived from the formula fitted by Zui et al. [21], He et al. [12], and Ren and Chen [22]. $\xi$ is a dimensionless parameter, defined as $\xi=l \sqrt{T / E I}$, which is used to identify the suspender and choose a reasonable formula.
Figure 21 depicts the calculation results of the suspender cable force in the abovementioned five methods. It can be seen from the broken line in the figure that the difference in the calculation result mainly exists for suspenders numbered 1,2, and 3, that is, suspenders with a length of $l \leq 18 \mathrm{~m}$. In addition, the calculated value of the eight suspenders numbered 1 significantly deviates from the true cable force. When the suspender length $l>18 \mathrm{~m}$, the results of the five calculation methods tend to coincide. Moreover, it is found that only the reference data for the calculated length, obtained by subtracting the length of the conduit from the total length, notably deviate from the true value. Because of the high stiffness and high natural frequency of the short suspender, the suspender tube has a significant influence on the entire suspender, which results in the difference in cable force measurement using the frequency method. In the calculation of the cable force of the short suspender, owing to the influence of external factors such as the conduit, the total length of the conduit cannot be simply reduced from the length considered in the calculation of the suspender cable force, and the calculation length needs to be modified.

\section{Formula for Cable Force Correction}

To verify the influence of different measurement periods on the suspender frequency, the same measurement data were obtained by measuring the frequency at $1 / 4$ of the same suspender at different time intervals. Environmental disturbance has a considerable influence on the short suspenders near the ends of the bridge. After replacing the suspender, the frequency data of each suspender in the measuring equipment are exported and represented as the broken line diagram depicted in Figure 22.

Two types of suspenders, PESC7-73 and PESC7-61, are selected. To obtain a more accurate calculation formula for the frequency cable force, this section considers suspender No. 3 as the boundary, and fits the long and short suspenders in the section. First, the formula for calculating the effective length is determined according to the characteristics of the short suspender. Because the lengths of the conduits of suspenders of different lengths do not differ significantly, the smaller the total length of the suspender, the greater the influence of the sleeve on the suspender. The formula for estimating the calculation length can be established as an index function based on $e$. Then, the objective function with undetermined parameters should be established, and the existing empirical formula for the cable force should be analysed. Based on the knowledge gained from previous studies, it can be concluded that for the existing engineering examples, when the slenderness ratio $L / D$ is less than 100 , considering the influence of the first-order term of the fundamental frequency $f$ on the cable force is more likely to yield an accurate and practical calculation formula for the cable force. Parameters of different types and the initial data at bridge completion are considered, and the necessary parameters are determined sequentially through the data processing program based on the initial data at bridge completion. 


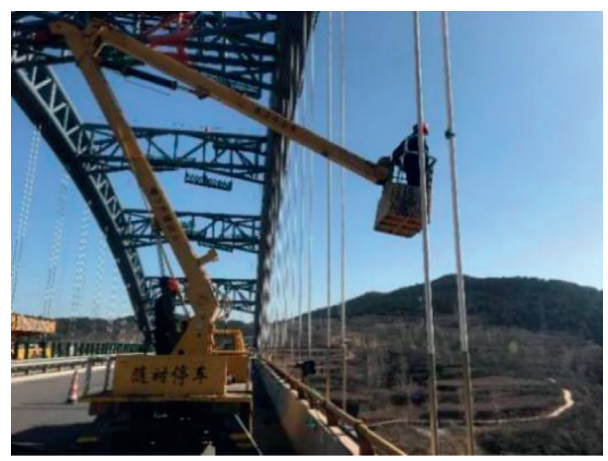

FIgURE 18: Testing of the suspender cable force.

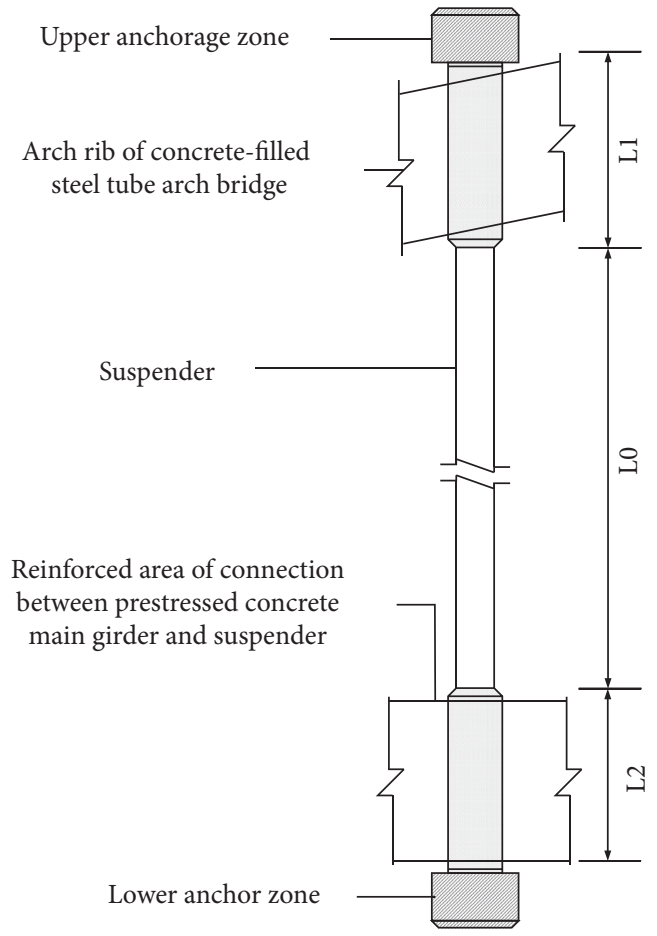

FIgURE 19: Structural sketch of suspender.

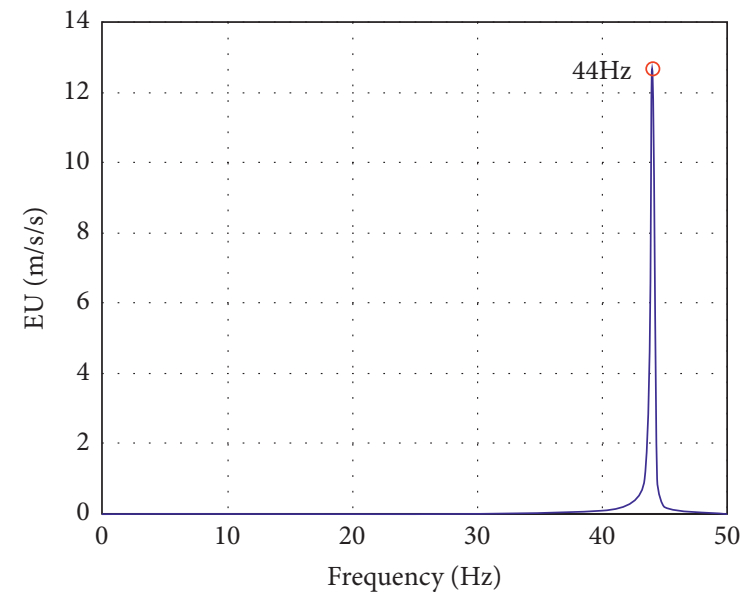

(a)

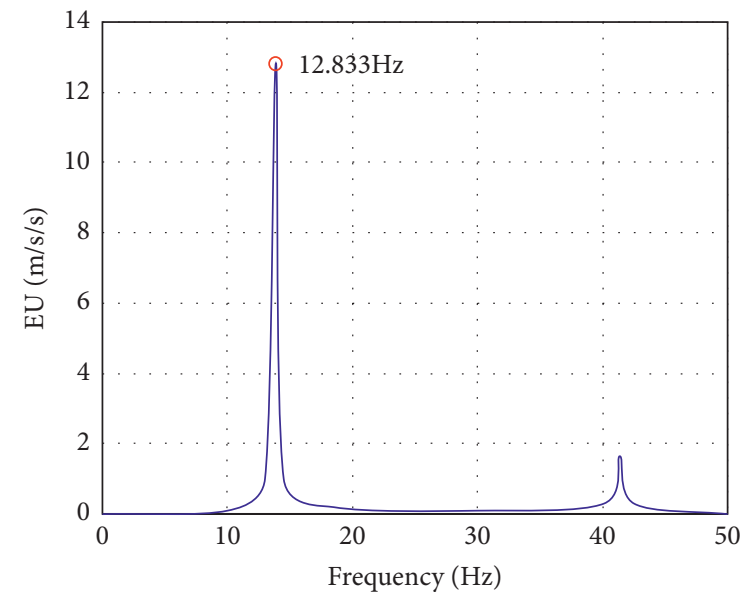

(b)

Figure 20: Continued. 


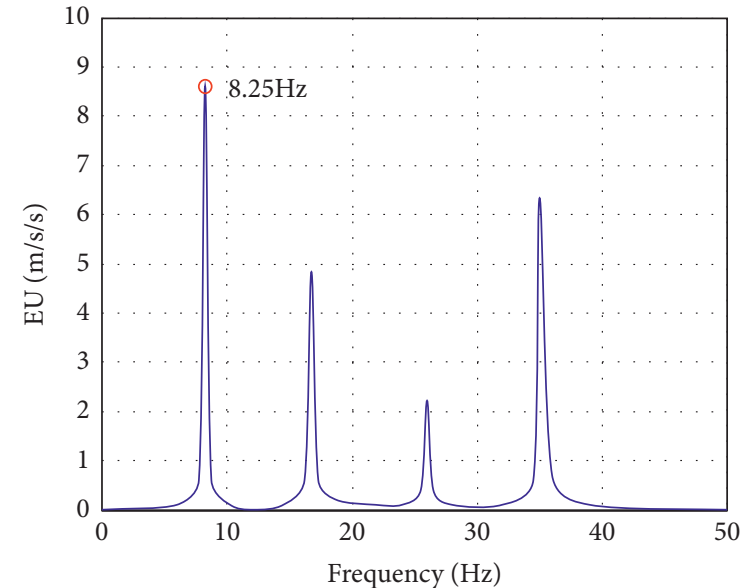

(c)

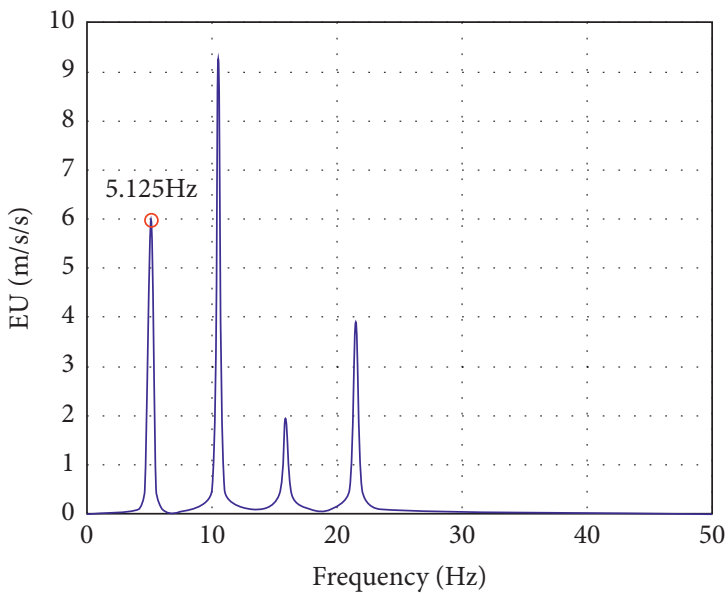

(e)

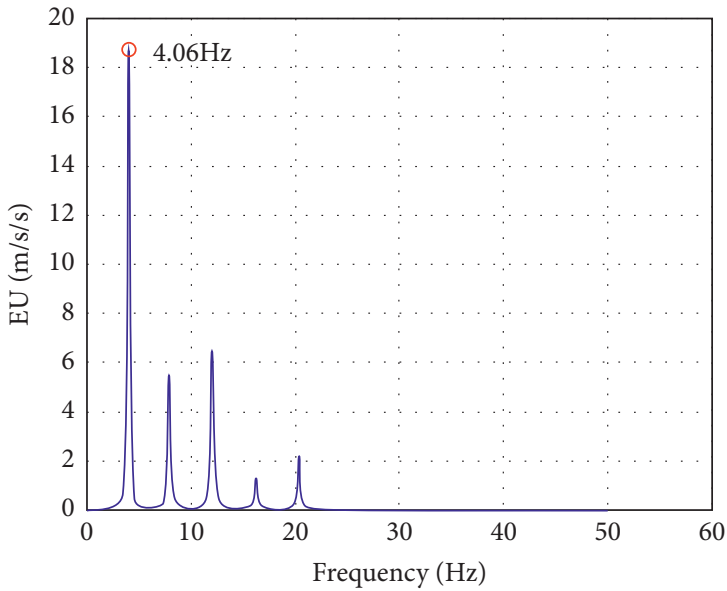

(g)

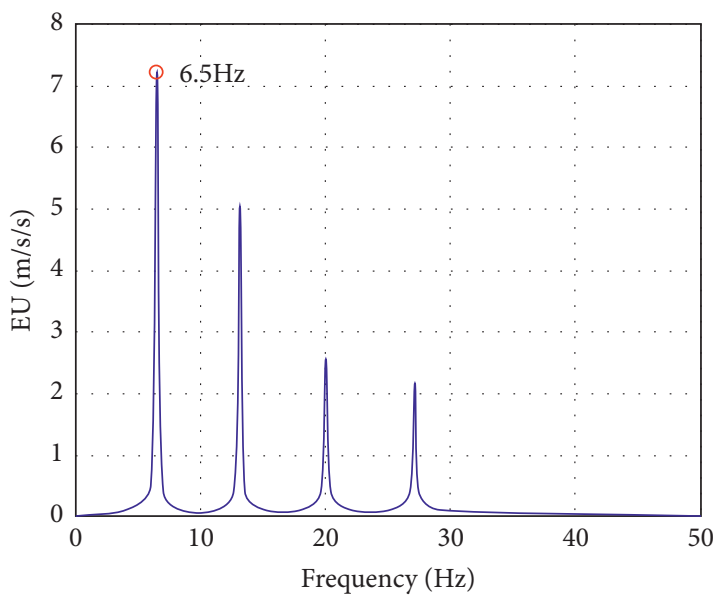

(d)

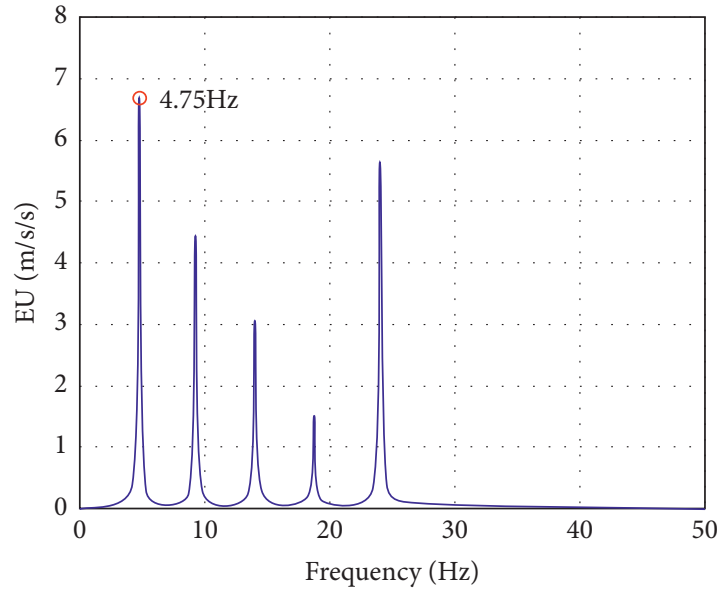

(f)

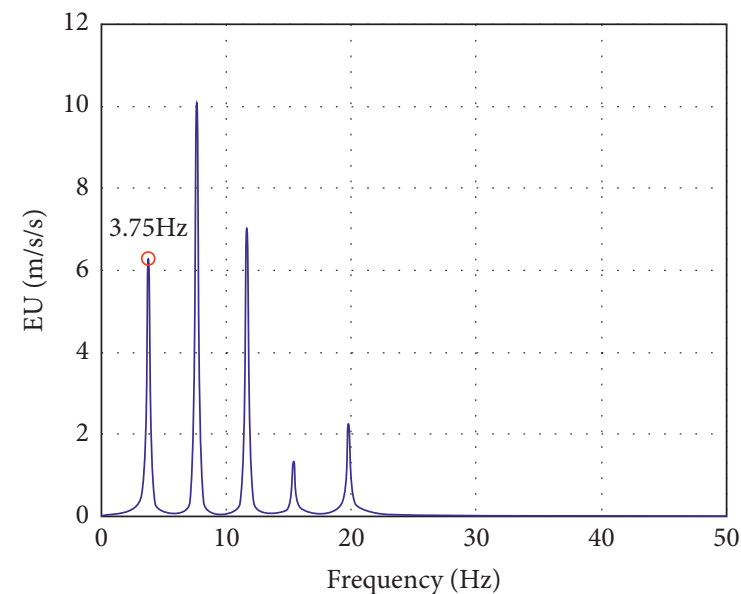

(h)

Figure 20: Continued. 


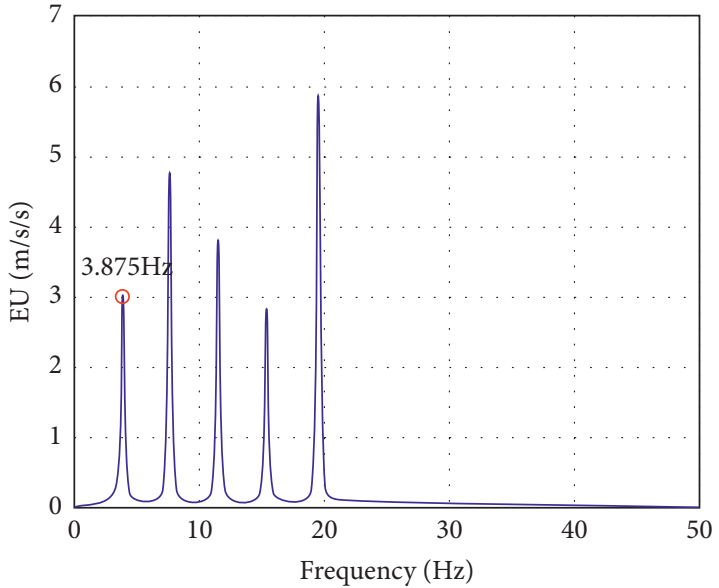

(i)

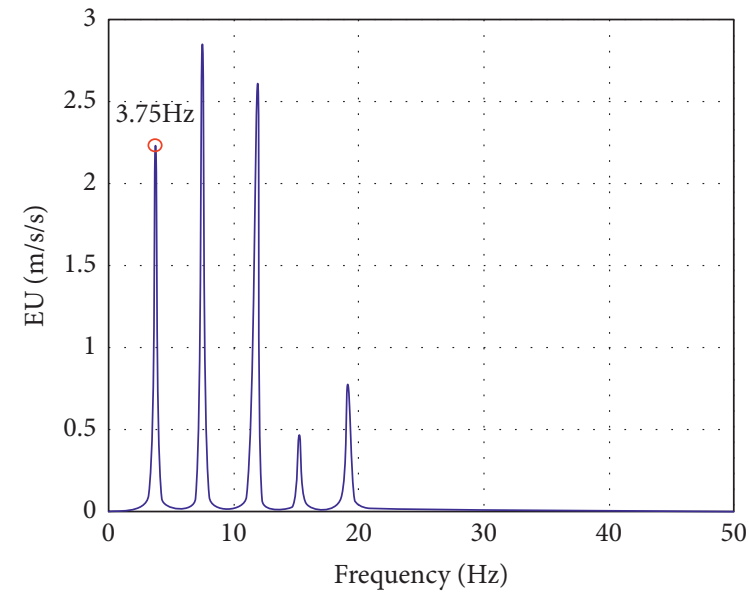

(j)

FIGURE 20: Frequency spectra of some suspenders: frequency charts of (a) S1n suspender; (b) S2n suspender; (c) S3n suspender; (d) S4n suspender; (e) S5n suspender; (f) S6n suspender; (g) S7n suspender; (h) S8n suspender; (i) S9n suspender; and (j) S10n suspender.

TABLE 7: Common calculation methods.

\begin{tabular}{lr}
\hline Calculation method & Calculation formula \\
\hline$T 1$ & $T=4 m l^{2}\left(f_{n}^{2} / n^{2}\right)-n^{2} \pi^{2}\left(E I / l^{2}\right)$ \\
$T 2$ & $T=4 \pi^{2} m l^{2}\left(f_{n}^{2} / y_{n}^{2}\right)-\left(E I / l^{2}\right) y_{n}^{2}$ \\
Model hi & $T=\left\{\begin{array}{l}4 m l^{2} f^{2}\left[1-2.2(c / f)-0.55(c / f)^{2}\right](17 \leq \xi) \\
4 m l^{2} f^{2}\left[0.865-11.6(c / f)^{2}\right](6 \leq \xi \leq 17) \\
4 m l^{2} f^{2}\left[0.828-10.5(c / f)^{2}\right](0 \leq \xi \leq 6)\end{array}\right.$ \\
Model chen & $T= \begin{cases}m l^{2} f^{2}[1+\sqrt{1-4.314(c / f)}]^{2}(20<\xi) \\
4 m l^{2} f^{2}\left[0.8881-12.7931(c / f)^{2}\right](9<\xi \leq 20) \\
4 m l^{2} f^{2}\left[0.8232-10.4375(c / f)^{2}\right](0 \leq \xi \leq 9)\end{cases}$ \\
Model ren & $T=\left\{\begin{array}{l}3.432 m l^{2} f^{2}-45.191\left(E I / l^{2}\right)(0 \leq \xi \leq 18) \\
m(2 l f-2.363 / l \sqrt{E I / m})^{2}(18<\xi \leq 210) \\
4 m l^{2} f^{2}(210<\xi)\end{array}\right.$
\end{tabular}

$c=\left(1 / l^{2}\right) \sqrt{E I / m} ; T$ is the tension of the cable; $m$ is the unit length mass of the boom; $F_{n}$ is the nth-order transverse vibration frequency of the boom; $E I$ is the bending stiffness of the cable; $L$ is the calculated length of the cable.

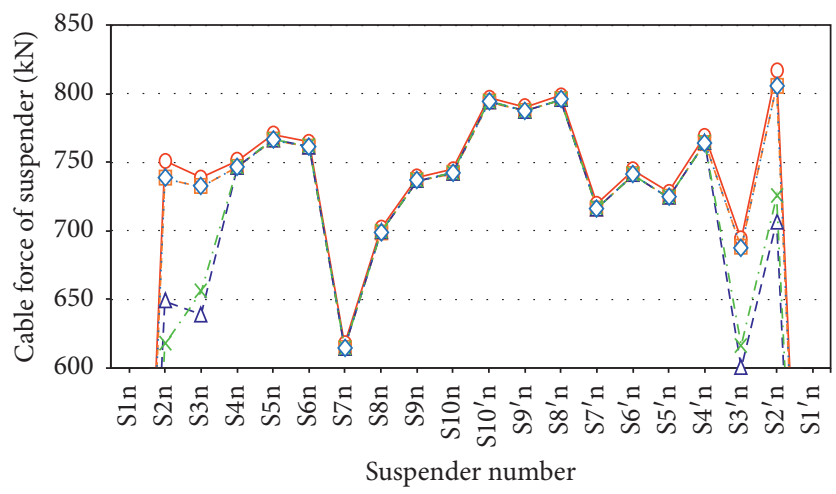

$$
\begin{array}{ll}
-\circ \text { T1 } & -\ngtr-\text { Model Chen } \\
- \text { - }- \text { T2 } & \cdots \diamond . . \text { Model Ren } \\
-\Delta-\text { Model Hi } &
\end{array}
$$

Figure 21: Calculated values of cable force by different methods. 


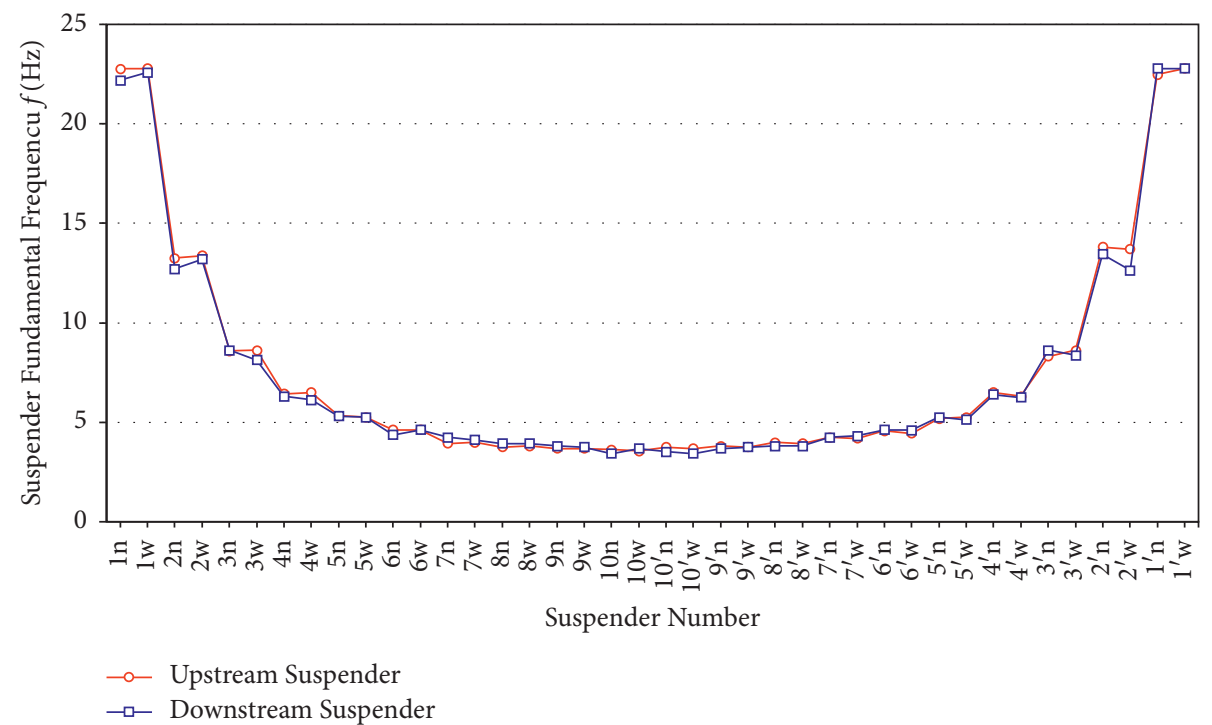

FIGURE 22: First-order vibration frequency of each suspender.

The objective function formula can be defined as follows:

$$
\begin{aligned}
& l_{0}=\alpha e^{\beta l}, \\
& T=A\left(l_{0} f_{1}\right)^{2}+B f_{1}+C\left(\frac{1}{l_{0}^{2}}\right) .
\end{aligned}
$$

The analysis of the objective function structure reveals that although the function contains the quadratic term of $f_{1},\left(l f_{1}\right)^{2}$, $f_{1}$, and $1 / l^{2}$ can be regarded as different primary variables; therefore, the multivariate linear fitting method is the simplest and most efficient. According to this method, the response parameters of 24 suspenders numbered 1-3 and $1^{\prime}-3^{\prime}$ are taken as the basic parameters, and the corresponding hanger linear density $m$ and bending stiffness EI are substituted into the coefficients of the above formula. After the calculation, the formula for calculating the actual engineering cable force based on data fitting is obtained as follows:

$$
T=4.08\left(l_{0} f_{1}\right)^{2}-1.935 m f_{1} \sqrt{\frac{E I}{m}}+1855.4\left(\frac{\pi^{2} E I}{l_{0}^{2}}\right) .
$$

The results are as follows:

$$
T=m l_{0}^{2}\left[4.08 f_{1}^{2}-1.9 \frac{f_{1}}{l_{0}^{2}} \sqrt{\frac{E I}{m}}+0.4342 \frac{\pi^{2} E I}{m l_{0}^{4}}\right] .
$$

Order $c=\left(1 / l^{2}\right) \sqrt{E I / m}$; therefore,

$$
\begin{aligned}
& T=m l^{2}\left[4.08 f_{1}^{2}-1.9 c f_{1}+0.4342 \frac{\pi^{2} E I}{m l^{4}}\right], \\
& l_{0}=1.2129 e^{0.1197 l} .
\end{aligned}
$$

The above are the cable force correction formulas of 24 suspenders numbered $1-3$ and $1^{\prime}-3^{\prime}$ under the influence of the natural frequency $f_{1}$ and bending stiffness $E I$ on the boundary conditions. The cable force is measured and calculated again according to the revised calculation formula. Figure 23 depicts the results, in which the maximum value of the cable force appears in the suspender numbered $S 1_{n},(772 \mathrm{kN})$, whereas the minimum value of the cable force appears in suspender No. X3 $3_{\mathrm{w}}^{\prime}(708 \mathrm{kN})$.

Similarly, through the data analysis of the existing cable force formula, we know that for the long suspender, the influence of the primary term with the fundamental frequency $f_{1}$ can be ignored, and then the fitting objective function formula can be defined as follows:

$$
T=A m l_{0}^{2} f_{1}^{2}+B E I \cdot\left(\frac{\pi}{l_{0}}\right)^{2} .
$$

Similarly, using the known data for fitting, the following formula is obtained:

$$
T=4.0206 m l^{2} f_{1}^{2}+0.182 E I \cdot\left(\frac{\pi}{l_{0}}\right)^{2} .
$$

Figure 24 depicts the results of the modified calculation formula of the cable force. In the new calculation results, the maximum cable force appears in suspender No. $S 10_{n}^{\prime}(751 \mathrm{kN})$, and the minimum cable force appears in suspender No. $\mathrm{S} 4_{\mathrm{w}}^{\prime}$ $(691 \mathrm{kN})$.

During the tensioning process, the tension control stress of boom Nos. 1-2 was $750 \mathrm{kN}$, and the tension control stress of the suspender Nos. 3-10 was $730 \mathrm{kN}$. The deviation rates from the results of the tension control stress for the short and long suspenders are shown in Figures 25 and 26, respectively. After replacing the suspender, the deviation rate between the measured suspender cable force and its corresponding tension control stress was maintained within $5 \%$. The fitting result achieves the desired effect, which can meet the requirement of engineering precision.

After the replacement of the suspender, the cable force of the new suspender was measured again by using a hydraulic Jack. Table 8 lists the measured cable force of the suspender, 


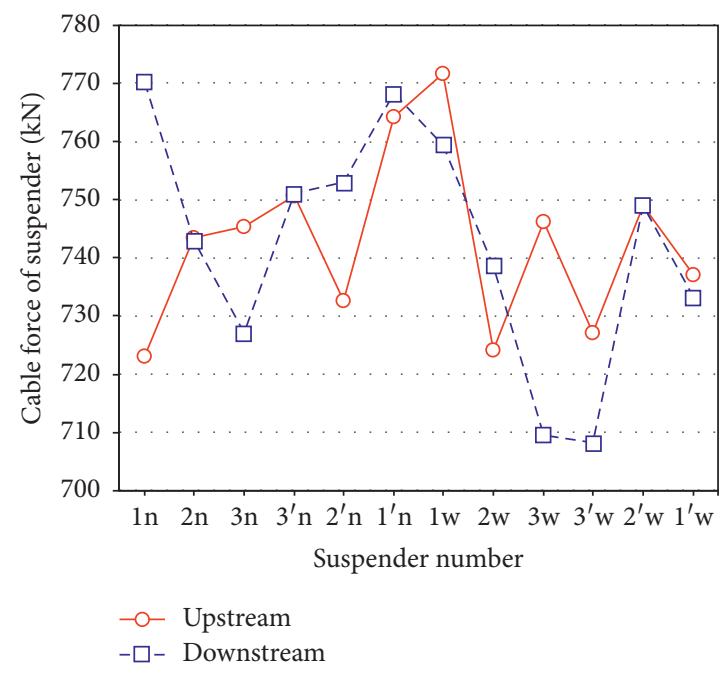

Figure 23: Cable force of short suspender after correction.

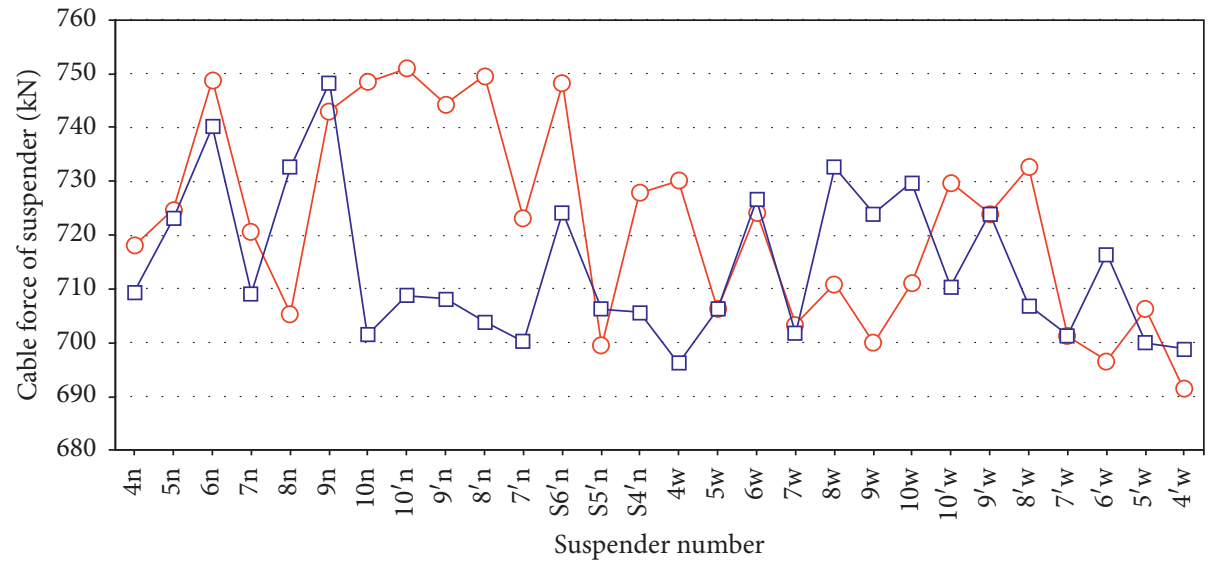

- - Upstream

$-\square-$ Downstream

Figure 24: Cable force of upstream long suspender after correction.

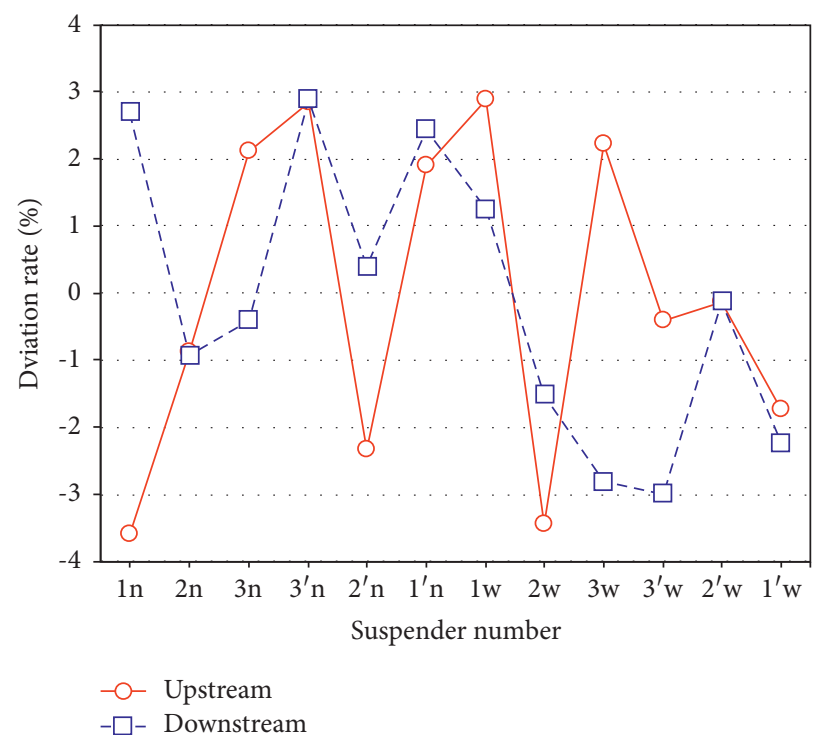

FIgURE 25: Deviation rate of short suspender. 


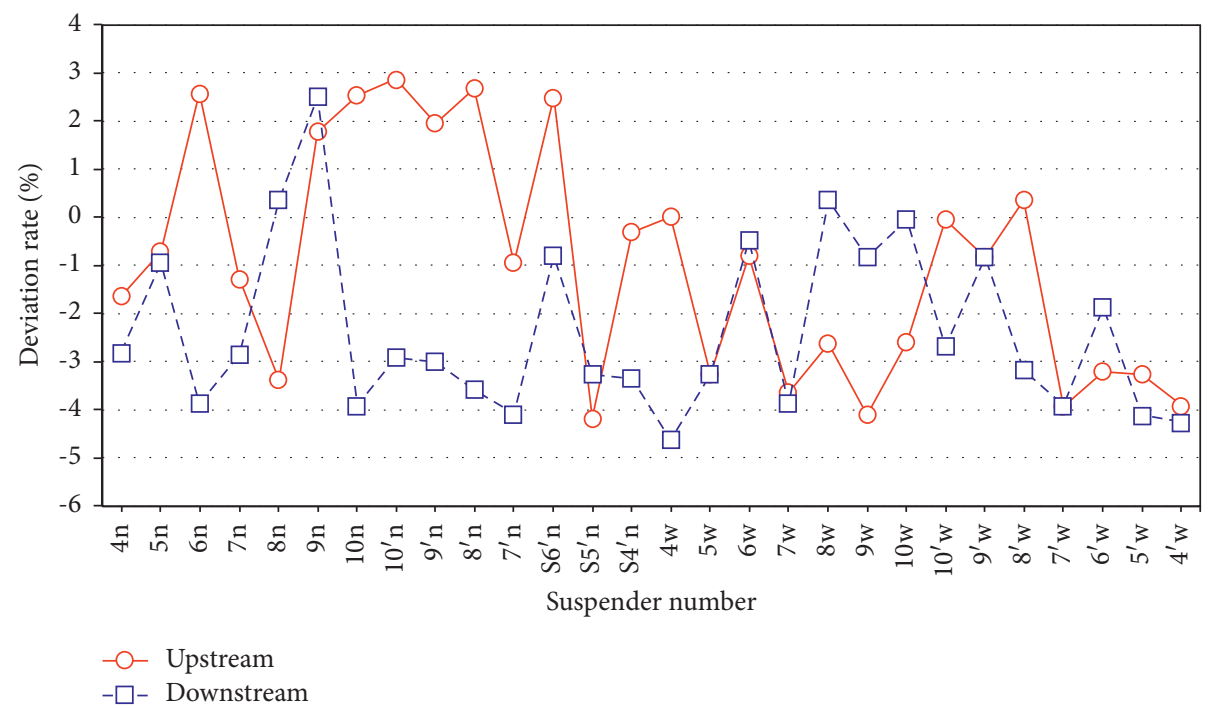

Figure 26: Deviation rate of long suspender.

TABLE 8: Error between calculated cable force and actual cable force.

\begin{tabular}{lccc}
\hline Suspender no. & Measured cable $(\mathrm{kN})$ & Calculated cable $(\mathrm{kN})$ & Deviation rate $(\%)$ \\
\hline S2n & 770 & 720.4 & -3.46 \\
S3n & 756.8 & 745.4 & -1.50 \\
S2w & 761 & 724.1 & -4.84 \\
S3w & 749.6 & 746.2 & -0.45 \\
X2n & 753 & 743 & -1.33 \\
X3n & 758 & 707 & -4.08 \\
X2w & 749 & 739 & -1.39 \\
X3w & 703 & 710 & 0.93 \\
\hline
\end{tabular}

the cable force calculated by the modified formula, and the deviation rate between them. By comparing the calculated results, the error rate between the measured results and the modified formula is found to be within $5 \%$.

Table 9 lists the cable force data recorded for some of the suspenders in previous years. After the suspender replacement construction of the bridge, the suspenders mentioned in the table were retested using the revised cable force calculation formula, and the results are depicted in Figure 27. The cable force of the replaced suspender was maintained near the tension control stress. Figure 28 clearly shows the difference in the cable force between the upstream and downstream suspenders of the same number. After eight suspenders were replaced, the difference in cable force of suspender No. $4_{\mathrm{n}}$ was found to be reduced from $144.21 \mathrm{kN}$ to $12.5 \mathrm{kN}$, which was the most significant change. The difference in cable force of the replaced suspender No. $2 \mathrm{n}$ decreased from $55.6 \mathrm{kN}$ to $21.7 \mathrm{kN}$, and that of the replaced suspender No. $3_{\mathrm{n}}$ decreased from $38.16 \mathrm{kN}$ to $29.61 \mathrm{kN}$. The smaller difference in cable force makes the cable force on both sides of the arch bridge more balanced, and the bridge structure is more reasonable in terms of the cable force distribution.

It can be seen from Figure 29 that after the replacement of the suspender, not only the cable force of the suspender at the replacement site but also that of the remaining
TABLE 9: Cable forces of some suspenders in previous years.

\begin{tabular}{lc}
\hline Suspender no. & Cable force $(\mathrm{kN})$ \\
\hline S1n & 633.44 \\
S2n & 600.48 \\
S3n & 613.11 \\
S4n & 627.10 \\
S5n & 682.08 \\
S6n & 775.70 \\
S7n & 725.32 \\
S8n & 843.64 \\
S9n & 843.96 \\
S10n & 827.75 \\
X1n & 669.34 \\
X2n & 656.12 \\
X3n & 574.95 \\
X4n & 771.31 \\
X5n & 747.45 \\
X6n & 734.69 \\
X7n & 758.47 \\
X8n & 804.49 \\
X9n & 816.82 \\
X10n & 806.22 \\
\hline
\end{tabular}

suspenders was altered. After the replacement of the short suspender No. S2 ${ }_{n}$, the cable force of the new suspender was higher by $20 \%$; after the replacement of suspender No. X 3 , 


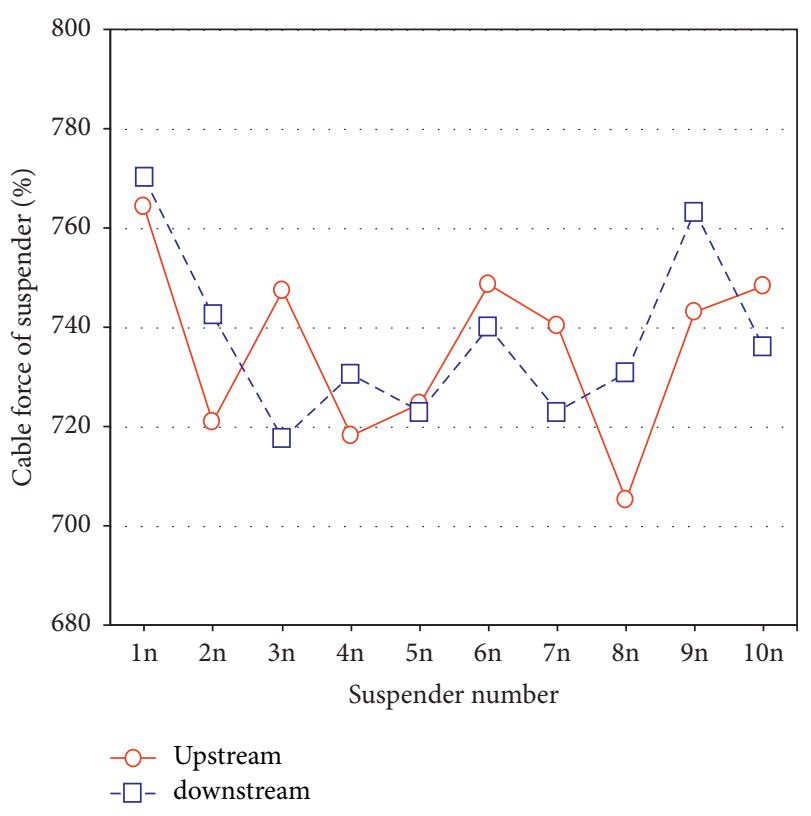

Figure 27: Calculated cable force of suspender Nos.1-10 after correction.

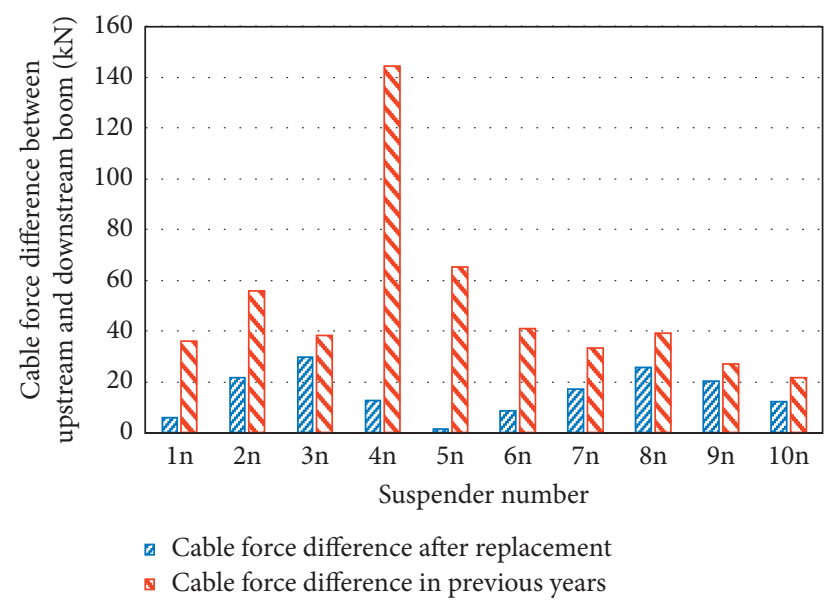

Figure 28: Cable force difference between upstream and downstream inner suspenders of the same number.

the cable force of the new suspender was higher by $23 \%$. The cable forces of individual long suspenders were considerably higher than the tension control stress, and the cable force of suspender No. $8_{\mathrm{n}}$ decreased by $16 \%$ in the upstream direction and $10 \%$ in the downstream direction. Thus, it is again proved that the suspender forces on both sides of the arch bridge are more balanced after the replacement of the suspender.

Furthermore, the above calculation results indicate that the cable force demonstrates a specific change during the long-term use of the original suspender because the effectiveness of the suspender decreases over time. In addition, it can be found that when there is a loss of suspender cable force (deviation rate is less than 0 ), the cable force of the nearby suspenders (adjacent suspenders and mutual inner/

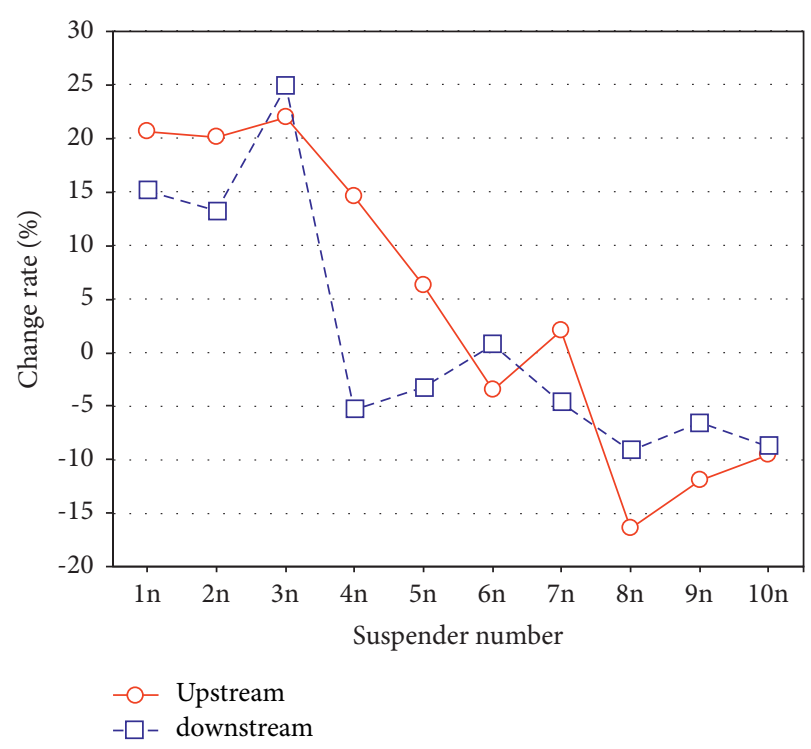

FIgURE 29: Change rate of suspender cable force.

outer suspenders) increases (deviation rate is greater than 0 ), indicating that the accumulation of the suspender diseases and the effect of load during the operation period indirectly cause the redistribution of the cable force over the entire arch bridge.

\section{Conclusion}

The main influencing factors of the suspender cable force test include the effective length of the suspender, bending stiffness, and boundary conditions. When the frequency method is used to measure the suspender, it is difficult to determine the frequency, including the fundamental frequency of the shorter suspender, as well as the calculation length solely based on the technical drawings. In the test for the suspender cable force, bending stiffness, ambient temperature, environmental vibration, and sleeve affect the measurement accuracy.

(1) The exact cable forces determined during this survey can be used as a basis for future evaluation and maintenance of the structure. These basic data are used to observe the evolution of structural conditions over time through comparison with subsequent measurements.

(2) When the frequency method is used to measure the tensile force of the suspender, the measurement environment should be stable to avoid interference when grasping the vibration frequency. The sensor should be arranged at $L / 2-L / 6$ to avoid the phenomenon of rapid decay of frequency, and then the ideal vibration spectrum of the boom should be obtained through comparative analysis.

(3) The smaller the total length of the suspender, the greater the influence of the sleeve and other boundary conditions. When using the frequency method to calculate the cable force of the short 
suspender, it is necessary to modify its effective length.

(4) The results indicate that the calculation error can be controlled within $5 \%$ by using the new fitting formula, which can meet the engineering specifications. After replacing the suspender, a comparison with the data from previous years shows that the cable force distribution of the upstream and downstream suspenders of the bridge is more coordinated.

(5) The temporary suspender method is used to replace the damaged suspender without interrupting the traffic, which ensures that the safety factor during the process of suspender replacement is adequate. In addition, it simplifies the on-site work, lowers replacement costs, and accelerates the construction process.

\section{Data Availability}

The raw/processed data required to reproduce these findings cannot be shared at this time as the data also form part of an ongoing study.

\section{Conflicts of Interest}

The authors declare that they do not have any commercial or associative interest that represents a conflict of interest in connection with the work submitted.

\section{Acknowledgments}

This work was supported by the National Nature Science Foundation of China (Grant Nos. 51678459 and 51378406) and the Technology Project of Shanxi Transportation Holdings Group Co., Ltd (Grant Nos. 19-JKKJ-8). Any opinions, findings, and conclusions expressed herein are those of the authors and do not necessarily reflect the views of the sponsors.

\section{References}

[1] R. Zhang, Z. Yang, and X. Zhu, "Practical formulas to calculate suspender tension based on frequency," Journal of Southwest Jiao Tong University, vol. 50, no. 5, pp. 823-829, 2015.

[2] Q. Yan, S. Liu, Z. Zhu, and D. Li, "Determining short suspender tension based on frequency method," Journal of Railway Science and Engineering, vol. 17, no. 10, pp. 25772585, 2020.

[3] L. Ma, "A highly precise frequency-based method for estimating the tension of an inclined cable with unknown boundary conditions," Journal of Sound and Vibration, vol. 409, pp. 65-80, 2017.

[4] W. Zhang, G. Wang, and Y. Sun, "Analysis on frequency and force of stay cable considering flexural rigidity," Journal of Highway and Transportation Research and Development, vol. 29, no. 7, pp. 64-69, 2012.

[5] F. Li, D. Du, and C. Li, "Research on replacement process of suspenders of tied arch bridge," Journal of Highway and Transportation Research and Development, vol. 09, pp. 110112, 2006.
[6] Y. Bing and S. Wang, "Replacement construction of hanger rods of neijiang basket arch bridge on chengyu expressway," World Bridges, vol. 04, pp. 60-63, 2008.

[7] Q. Su, G. Yang, and C. Wu, "Analysis of effect of suspender replacement on mechanical behavior of main bridge of Jiubao Bridge," Bridge Construction, vol. 04, pp. 15-19, 2011.

[8] R. Lan, G. Jiang, H. Wang, T. Hao, L. Wang, and Q. Liang, "Research on the suspender replacement process of arch bridge based on the measured displacement correction," IEEE Access, vol. 8, pp. 226952-226961, 2020.

[9] Z. Sun, S. Ning, and Y. Shen, "Failure investigation and replacement implementation of short suspenders in a suspension bridge," Journal of Bridge Engineering, vol. 22, no. 8, Article ID 05017007, 2017.

[10] D. Feng, C. Mauch, S. Summerville, and O. Fernandez, "Suspender replacement for a signature bridge," Journal of Bridge Engineering, vol. 23, no. 11, Article ID 05018010, 2018.

[11] B.-H. Kim and T. Park, "Estimation of cable tension force using the frequency-based system identification method," Journal of Sound and Vibration, vol. 304, no. 3, pp. 660-676, 2007.

[12] W. He, H. Chen, B. Wang, and F. Hu, "Study of suspender tension measurement based on frequency method with complex boundary conditions," China Civil Engineering Journal, vol. 45, no. 3, pp. 93-98, 2012.

[13] W.-H. Wu, C.-C. Chen, Y.-C. Chen, G. Lai, and C.-M. Huang, "Tension determination for suspenders of arch bridge based on multiple vibration measurements concentrated at one end," Measurement, vol. 123, pp. 254-269, 2018.

[14] B. Yan, J. Yu, and M. Soliman, "Estimation of cable tension force independent of complex boundary conditions," Journal of Engineering Mechanics, vol. 141, no. 1, Article ID 06014015, 2015.

[15] S. E. H. A. M. Zarbaf, M. Norouzi, R. J. Allemang, V. J. Hunt, A. Helmicki, and D. K. Nims, "Stay force estimation in cablestayed bridges using stochastic subspace identification methods," Journal of Bridge Engineering, vol. 22, no. 9, Article ID 04017055, 2017.

[16] C.-C. Chen, W.-H. Wu, S.-Y. Chen, and G. Lai, "A novel tension estimation approach for elastic cables by elimination of complex boundary condition effects employing mode shape functions," Engineering Structures, vol. 166, pp. 152-166, 2018.

[17] B. Xu, D. Dan, and Y. Zou, "Accurate identification method and practical formula of suspender tension based on trisegment suspender dynamic model," Engineering Structures, vol. 200, Article ID 109710, 2019.

[18] H. Ma, Z. Chen, H. Liu, Z. Li, and M. Guo, "Study on calibration of cable tension of cable-supported structures based on frequency tests," Spat. Struct., vol. 24, no. 4, pp. 35-41, 2018.

[19] J. B. Sun, Z. Z. Zhao, and H. H. Zhao, "Measuring methods of cable tension in cable-stayed bridges," Advanced Materials Research, vol. 295-297, pp. 1230-1235, 2011.

[20] G. Nugroho, H. Priyosulistyo, and B. Suhendro, "Evaluation of tension force using vibration technique related to string and beam theory to ratio of moment of inertia to span," Procedia Engineering, vol. 95, pp. 225-231, 2014.

[21] H. Zui, T. Shinke, and Y. Namita, "Practical formulas for estimation of cable tension by vibration method," Journal of Structural Engineering, vol. 122, no. 6, pp. 651-656, 1996.

[22] W. Ren and G. Chen, "Pracitical formulas to determine cable tension by using cable fundamental frequency," China Civil Engineering Journal, vol. 20, no. 11, pp. 26-31, 2005. 